\title{
Epigeal spider responses to fertilization and plant litter: testing biodiversity theory at the ground level
}

L. Brian Patrick ${ }^{1}$, Mark W. Kershner ${ }^{2}$ and Lauchlan H. Fraser ${ }^{3}$ : ${ }^{1}$ Department of Biological Sciences, Dakota Wesleyan University, 1200 W. University Avenue, Mitchell, South Dakota 57301, USA. E-mail: brpatric@dwu.edu; ${ }^{2}$ Department of Biological Sciences, Kent State University, Kent, Ohio 44242, USA; ${ }^{3}$ Department of Natural Resource Sciences, Thompson Rivers University, 900 McGill Road, Kamloops, British Columbia V2C 5N3, Canada

\begin{abstract}
Recent studies of nutrient additions to terrestrial ecosystems have focused on the "aerial" portion of the food web associated with living plants. These studies showed nutrient loading increased arthropod abundance and biomass, but decreased diversity. However, none of these studies explicitly examined nutrient loading effects on epigeal arthropods. To test nutrient loading effects on epigeal spiders and on individual species within a temperate-latitude grassland community, we used pitfall traps to sample spiders for four years within 24 large $\left(314 \mathrm{~m}^{2}\right)$ plots in which we manipulated nutrients (NPK fertilizer) and plant litter (litter removed or left in place). We measured the diversity, abundance, biomass, and community structure responses of the spider community, and of wolf spiders (Lycosidae) and linyphiid spiders (Linyphiidae), as well as the abundance and biomass responses of the six most common species. We hypothesized increased nutrient loading would increase epigeal spider abundance and biomass but decrease diversity. Contrary to predictions, spider species richness, diversity, and biomass were not significantly affected by fertilization, while fertilization resulted in significantly increased abundance. Also contrary to predictions, plant litter did not affect any of these variables. Linyphiid spiders had the strongest responses to fertilization, with significantly increased abundance and biomass, and, contrary to predictions, increased species richness in fertilized plots. Wolf spiders responded more closely to predictions. Our results indicate that the epigeal spider community does not respond as would be predicted by biodiversity-productivity theory. This underscores the need to integrate the largely detritus-based epigeal community into current biodiversity-productivity theory.
\end{abstract}

Keywords: Araneae, Linyphiidae, Lycosidae, enrichment, disturbance, nitrogen

Human activity has resulted in a significant increase in the global nitrogen $(\mathrm{N})$ pool through fertilization and increased atmospheric N deposition (Vitousek et al. 1997; Fenn et al. 2003; Galloway et al. 2003). Typical plant community responses include decreased plant species richness, increased standing crop biomass, and the limitation of community composition to a few dominant species (Hector et al. 1999; Tilman et al. 2002; Suding et al. 2005; Patrick et al. 2008a). This research has provided substantive support for biodiversityproductivity theory, which predicts declines in local and regional richness as one moves from mesotrophic to eutrophic systems (Grime 1973; McCann 2000; Worm \& Duffy 2003; Suding et al. 2005; Chalcraft et al. 2008). Similarly with terrestrial arthropods, increased nutrient loading has been linked with decreased species richness and increased abundance, particularly among those species most closely linked to the living-plant portion of the food web (Knops et al. 1999; Haddad et al. 2000, 2001; but see Patrick et al. 2008b). This "eutrophication effect" (Fenn et al. 2003) can result in significant biodiversity loss and potential decline in important ecosystem functions, such as ecosystem stability (McCann 2000; Larsen et al. 2005).

Previous studies of nutrient loading have focused on the portions of the food web closely tied to living plant material; e.g., the "aerial" arthropod community associated with the upper portions (e.g., stems) of plants (Knops et al. 1999; Haddad et al. 2000, 2001). Although there is evidence to support the eutrophication effect on aerial arthropod diversity, less is known regarding how nutrient loading affects the epigeal (ground-level) arthropod community. A differential response by the epigeal arthropod community may result from it being more closely tied to the detritus-based portion of the food web (Halaj \& Wise 2002). Despite the important role it may play, the epigeal arthropod community remains an understudied food web component (Wardle 2002; Hättenschwiler et al. 2005; Cross et al. 2006).

Nutrient loading also increases plant litter production (Long et al. 2003; Patrick et al. 2008a), which can increase the basal food resource for the detrital community and increase detritivore and epigeal predator abundances (Halaj et al. 2000; Halaj \& Wise 2002; Moore et al. 2004). Furthermore, plant litter increases habitat complexity, which can also increase arthropod abundance and diversity (Lawton 1983; Strong et al. 1984; Rypstra et al. 1999). Although more plant litter production could increase detritivore and epigeal predator abundance and biomass (Halaj et al. 2000), a reduction in litter diversity could result in decreased diversity of detritivores and epigeal predators (Hättenschwiler \& Gasser 2005; Wardle 2006), mirroring the aerial community response to nutrient loading.

Spiders, in particular, are abundant generalist predators (Wise 1993) that can significantly impact terrestrial food webs (Wise et al. 1999), and epigeal spiders (e.g., Lycosidae and Linyphiidae) are closely linked to the detritivore community (Wise et al. 1999; Chen \& Wise 1999; Wise 2006). The abundance of epigeal spiders is limited ultimately by the abundance of their mainly detritivorous prey via bottom-up forces through the detritus-based portion of the food web (Chen \& Wise 1999; Wise et al. 1999; Wise 2004, 2006). Thus, increasing plant detritus can increase spider abundance by increasing the quantity of food available to their detritivorous prey (Chen \& Wise 1999; Wise et al. 1999; Wise 2004). Increased detritus also enhances habitat structure for hiding and web building (Uetz 1979, 1991; Rypstra et al. 1999), which 
can also moderately increase the local richness of the spider community (Rypstra et al. 1999), also differentially affecting individual spider species.

Even though spider abundance may increase, spider diversity may not increase proportionally because the reduced diversity of plant detritus can limit predator diversity in the detrital food web (Hättenschwiler \& Gasser 2005; Wardle 2006). Thus, it is reasonable to expect that predators dependent upon the detritivore food web may have the same response to fertilization as predators more closely associated with the aerial food web. Even though more plant litter is produced, increasing the resource base of the detritivore food web, lower litter diversity likely begets lower detritivore and detritivore-predator diversity (Hättenschwiler \& Gasser 2005; Wardle 2006). Interestingly, no epigeal spider studies (focused strictly on cursorial spiders; e.g., wolf spiders) have looked at the spider diversity response to basal resource manipulation. Moreover, no studies have examined responses of the predominantly epigeal spider family Linyphiidae (wandering sheet/tangle-web builders) that may patrol multiple webs at ground level (Uetz et al. 1999).

Here we report the results of a four-year study that investigated the response of the epigeal spider community to experimental manipulations of NPK fertilization and plant litter availability in a temperate-latitude grassland. We measured the diversity, abundance, biomass, and community structure responses of the entire epigeal spider community, the spider families Lycosidae and Linyphiidae, and the dominant individual spider species. Our goal was to integrate the detrital food web into biodiversity-productivity theory through insight gained from the responses of predators that rely largely on the detritivore food web. Based on previous studies that sampled the aerial arthropod community responses to nutrient loading (e.g., Knops et al. 1999; Haddad et al. 2000, 2001), we tested two hypotheses: (1) fertilization will cause spider biomass and abundance to increase and spider species richness to decrease, and (2) the presence of plant litter will moderately increase spider species richness, though this effect will be dampened in fertilized plots.

\section{METHODS}

Study site and experimental design. - The study was done at the 163.5 ha Bath Nature Preserve (BNP: $41^{\circ} 10^{\prime} 36.2^{\prime \prime} \mathrm{N}$, $\left.81^{\circ} 38^{\prime} 58.7^{\prime \prime} \mathrm{W}\right)$, Bath Township, Summit County, Ohio, USA, in a 16 ha section of grassland. Until the early 1980s, the study site was a hay meadow, harvested one or many times per year. Since then, the area has been mown annually in late August to early September, and the mown vegetation has been left on the field. The dominant vegetation is an herbaceous, graminoid community largely dominated by cool-season $\mathrm{C}_{3}$ grasses, e.g., Bromus inermis Leyss., Lolium arundinaceum (Schreb.) Darbysh, Phleum pratense L., and Anthoxanthum odoratum L. The site is moderately productive relative to other grasslands within the upper Midwest and across the USA (Patrick et al. 2008a). The dominant soil type is Ellsworth silt loam (ElB), which consists of moderately well drained, moderately deep to deep soils formed in silty clay loam or clay loam glacial till of the Wisconsin Age (Ritchie \& Steiger 1974).

During August 2001, twenty-four 20-m diameter circular plots $\left(314 \mathrm{~m}^{2}\right)$ were established. These experimental plots were separated by at least $20 \mathrm{~m}$ and were at least $30 \mathrm{~m}$ away from any other habitat. Treatments were applied in a $2 \times 2$ factorial design of fertilizer $(+\mathrm{F}=$ fertilizer added, $-\mathrm{F}=$ no fertilizer $)$ and plant litter $(-\mathrm{L}=$ litter removed, $+\mathrm{L}=$ litter left in situ after yearly mowing) with control plots characterized as no fertilization and plant litter left in situ $(+\mathrm{L} /-\mathrm{F})$, resulting in six replicates per treatment. Hereafter, all references to "litter" refer to the previous year's mown vegetation and any vegetation senesced and found within the sampling quadrat after standing crop removal. In April 2002 and continuing each April through 2005, Scotts brand Osmocote 8-9 month Slow Release Fertilizer 19-6-12 (NPK; Scotts, Marysville, Ohio USA) was applied at $20 \mathrm{gNm}^{-2}$ in fertilized plots, well above the Köchy \& Wilson (2005) $15 \mathrm{~g} \mathrm{Nm}^{-2} \mathrm{yr}^{-1}$ threshold necessary to induce a eutrophication effect in grasslands and other habitats. We could not exclude ambient wet/dry atmospheric $\mathrm{N}$ deposition, though deposition rates from 1990 to 2005 were relatively low at $\sim 1.01 \mathrm{~g} \mathrm{~N} \mathrm{~m}^{-2} \mathrm{yr}^{-1}$ at a nearby monitoring site in Lykens (162 km west of our study site), Ohio, USA, and $\sim 0.93 \mathrm{~g} \mathrm{~N} \mathrm{~m}^{-2} \mathrm{yr}^{-1}$ at another nearby monitoring site in Mercer Co. (G.K. Goddard site, $96 \mathrm{~km}$ east of our study site), Pennsylvania, USA (US EPA 2005). Within two days of annual mowing of the whole site by the local township with a large tractor and brush hog mower (autumn 2001-2004), litter was removed from litter-removal treatments using a small $23 \mathrm{hp}$ lawn tractor with a pull-behind $8 \mathrm{hp}$ AgriFab Mow-N-Vac trailer attachment (Agri-Fab, Sullivan, Illinois, USA).

Spider community sampling.--Spiders were collected using four pitfall traps in each of the 24 experimental plots $(n=96$ total pitfall traps). Within each plot, a single trap was placed $5 \mathrm{~m}$ from the center of the plot at each of four magnetic compass directions (northeast, northwest, southeast, and southwest). Each trap consisted of a $10 \mathrm{~cm}$ diameter, $18 \mathrm{~cm}$ tall PVC sleeve into which a $710-\mathrm{mL}$ plastic cup was inserted and filled to $\sim 4 \mathrm{~cm}$ with a 50/50 water/propylene glycol mixture. To deter trap raiders (e.g., microtine mammals), prevent captured spiders from climbing out of the trap, and prevent precipitation from directly flooding the trap, an $8-\mathrm{cm}$ powder funnel with a base enlarged to $\sim 3 \mathrm{~cm}$ was inserted and a $15 \mathrm{~cm} \times 15 \mathrm{~cm}$ board was placed over each trap, leaving $\sim 3 \mathrm{~cm}$ clearance. Starting mid to late May (mid-July during 2004) and continuing through mid to late August, traps were alternately left open for two weeks and closed for two weeks. This resulted in three sampling periods each year during 2002, 2003, and 2005. During 2004, only the second and third sampling periods were collected. When each two-week sampling period ended, the plastic cups were removed, the contents collected and preserved in $70 \%$ ethyl alcohol, and the PVC sleeve was tightly capped. Although pitfall traps do not capture all spiders in the community, they are an effective sampling technique for determining the relative abundance and species richness of epigeal spiders (Greenslade 1964; Phillips \& Cobb 2005). Spiders captured in each trap were identified to species for all mature specimens (taxonomic names follow Platnick 2012), and to family for all immature specimens, and exact numbers of species/families within in each trap were recorded and dried at $70^{\circ} \mathrm{C}$ for $72 \mathrm{~h}$ to determine species-specific biomasses to the nearest $0.0001 \mathrm{~g}$. Lacking sufficient numbers captured within a trap, some 
extremely small species did not register a biomass, and their biomass was recorded as " $0.000001 \mathrm{~g}$ " to differentiate them from true zeroes in analyses.

Statistical analyses.-We tested the effects of fertilization, plant litter, and the interaction of fertilization and litter on the abundance, biomass, species richness (SR), and effective Shannon's diversity $\left(e^{H^{\prime}}\right.$, where $H^{\prime}$ is the Shannon diversity index) of (1) all mature spiders (Araneae), (2) lycosid and linyphiid spiders and (3) abundance and biomass of the six most abundant spider species. We used $e^{H^{\prime}}$ to correct for differences in species richness that might have resulted from differential spider abundances (Ricklefs \& Miller 2000; Haddad et al. 2000). To calculate the average SR within a plot, we summed the total number of spider species caught in each trap, then averaged this SR for each of the four traps within a plot within a sampling period (including zeroes for traps where no spiders were captured), then averaged these SRs for each plot across sampling periods in a year, yielding $n=24$ samples within each year. The same method was used to calculate the average abundance, biomass and $e^{H^{\prime}}$ within a plot within a year, also yielding $n=24$ samples within each year. Correlations and regressions of these spider responses with plant species richness (plant SR) and standing crop biomass utilized data from Patrick et al. (2008a).

To analyze trends per year and per treatment in abundance, biomass, SR, and $e^{H^{\prime}}$ we used SAS software version 8.01 (SAS Institute, Inc. 1999) to calculate a Generalized Linear Mixedeffect Model (GLMM) in PROC MIXED with Type III effects based upon the covariance structure of compound symmetry, and Gaussian distribution of errors. The various models used the different response variables (biomass, SR, $e^{H^{\prime}}$, abundance), and for the predictor variables used fertilized vs. unfertilized, litter removed vs. litter left in situ, year, and their factorial interactions, with year as the repeated predictor. When year was detected as a significant effect for a response variable, we tested for treatment effects within a year and again used SAS to calculate a GLMM in PROC MIXED with Type III effects based upon the covariance structure of compound symmetry, Gaussian distribution of error, with fertilization, litter, and the factorial interaction of fertilization and litter as predictor variables.

To assess treatment effects on aggregate biotic and abiotic components in our system, we applied nonmetric multidimensional scaling (NMS: Kruskal 1964) using PC-ORD (McCune $\&$ Mefford 2006). For 2005, variables used for each of the 24 plots were average spider species richness per plot and four variables used in a previously published analysis (Patrick et al. 2008a): average plant litter biomass, average PAR per plot, average percent soil moisture per plot, and average percent soil organic content per plot, resulting in a matrix with five columns and 24 rows (plots). The same analysis was run a second time with the same variable, except Linyphiidae species richness replaced spider species richness. Because (1) NMS is scale sensitive, (2) these variables are on radically different measurement scales, and (3) variables have an enormous range of values between variables, data were transformed to proportions relative to the highest value for each variable (i.e., each value in a column was divided by the largest value in that column, creating a unitless range from $0-1$ for each column). The NMS analysis was run with Sørensen distance, time as the random seed for the starting configuration, 9999 runs stepping down from 5 to 1 dimensions with the real data, 999 Monte Carlo runs to assess the probability of a similar final stress obtained by chance, and a 0.005 stability criterion. Additionally for 2005 and to support NMS analyses with stable results, we used PC-ORD (McCune \& Mefford 2006) to run the multi-response permutation procedure (MRPP: Mielke 1984) to test for the hypothesis of no difference among treatments. The MRPP used Sørensen distance with the four treatments as the a priori groupings, resulting in a matrix with five columns (biotic and abiotic variables) and 24 rows (plots) and was calculated with all four treatments together, and for pairwise comparisons between treatments to test for the strength of difference between individual treatments.

\section{RESULTS}

General trends.-A total of 13,174 spiders from 14 families was captured during 14,784 trap nights. Of this total, 2515 spiders were immature and from 11 families, while the remaining 10,659 spiders were mature and from 94 species and 12 families (Table 1). Lycosidae was the most commonly captured spider family, with 6577 mature specimens $(61.7 \%$ of all mature spiders captured) from 20 species, while Linyphiidae was the second most commonly captured spider family with 3200 mature specimens $(30.0 \%$ of all mature spiders captured) from 34 species. Together these two families represented 9777 (91.7\% of all mature spiders captured) specimens from 54 species (57.4\% of all species captured). Spider diversity, corrected for abundance with $e^{H^{\prime}}$, was significantly affected by fertilization and by year, but not by litter (Table 2). The factorial interactions between fertilization and year, fertilization and litter, litter and year, and the fully factorial interaction of fertilization by litter by year were not significant (Table 2). Because of the significance of year (Fig. 1), we tested for treatment effects on spider diversity within each year and by 2005 (Table 3) neither fertilization, nor litter nor their interaction was significant.

Fertilization significantly affected Araneae (all spiders) abundance but not Araneae SR or Araneae biomass (Table 2, Fig. 2A-C). Moreover, fertilization effects were significant for Linyphiidae SR, abundance and biomass (Table 2, Fig. 2D-F), as well as for Lycosidae SR and abundance (Table 2, Fig. 2G$\mathrm{H}$ ), but not for Lycosidae biomass (Table 2, Fig. 2I). All response variables were significantly affected by year (Table 2), and Araneae SR and abundance, and Linyphiidae SR, abundance and biomass had significant fertilization and year interactions.

Neither Araneae SR nor Lycosidae SR were significantly correlated with abundance $(r=0.335$ and $r=-0.190$, respectively), but Linyphiidae SR was well correlated with abundance $(r=0.857$; Fig. 3A-C). As with abundance, biomass was only correlated in the Linyphiidae SR $(r=$ 0.629; Fig. 3D-F). Although Araneae SR was not significantly correlated with plant SR ( $r=0.276$; Fig 4A), Linyphiidae SR was negatively correlated with plant SR $(r=-0.400)$, and Lycosidae SR was positively correlated with plant SR $(r=$ 0.639; Fig. 4B-C). Araneae SR was also not correlated with standing crop biomass ( $r=0$; Fig. 4D), while Linyphiidae SR was positively correlated and Lycosidae SR was negatively correlated with standing crop biomass $(r=0.629$ and $r=$ -0.425 , respectively; Fig. 4E-F). 
Table 1.-Total numbers of each family and species of spider captured during the four year manipulative experiment. " $+\mathrm{L} /-\mathrm{F}$ " represents the control treatment of unfertilized plots with litter left in situ, " $-\mathrm{L} /-\mathrm{F}$ " represents the unfertilized with litter removed treatment, " $+\mathrm{L} /+\mathrm{F}$ " represents the fertilized with litter left in situ treatment, " $-\mathrm{L} / \mathrm{F}$ " represents the fertilized with litter-removed treatment, and "Total" represents the total number caught. Immature spiders were classified as "unidentified," and family names are in bold.

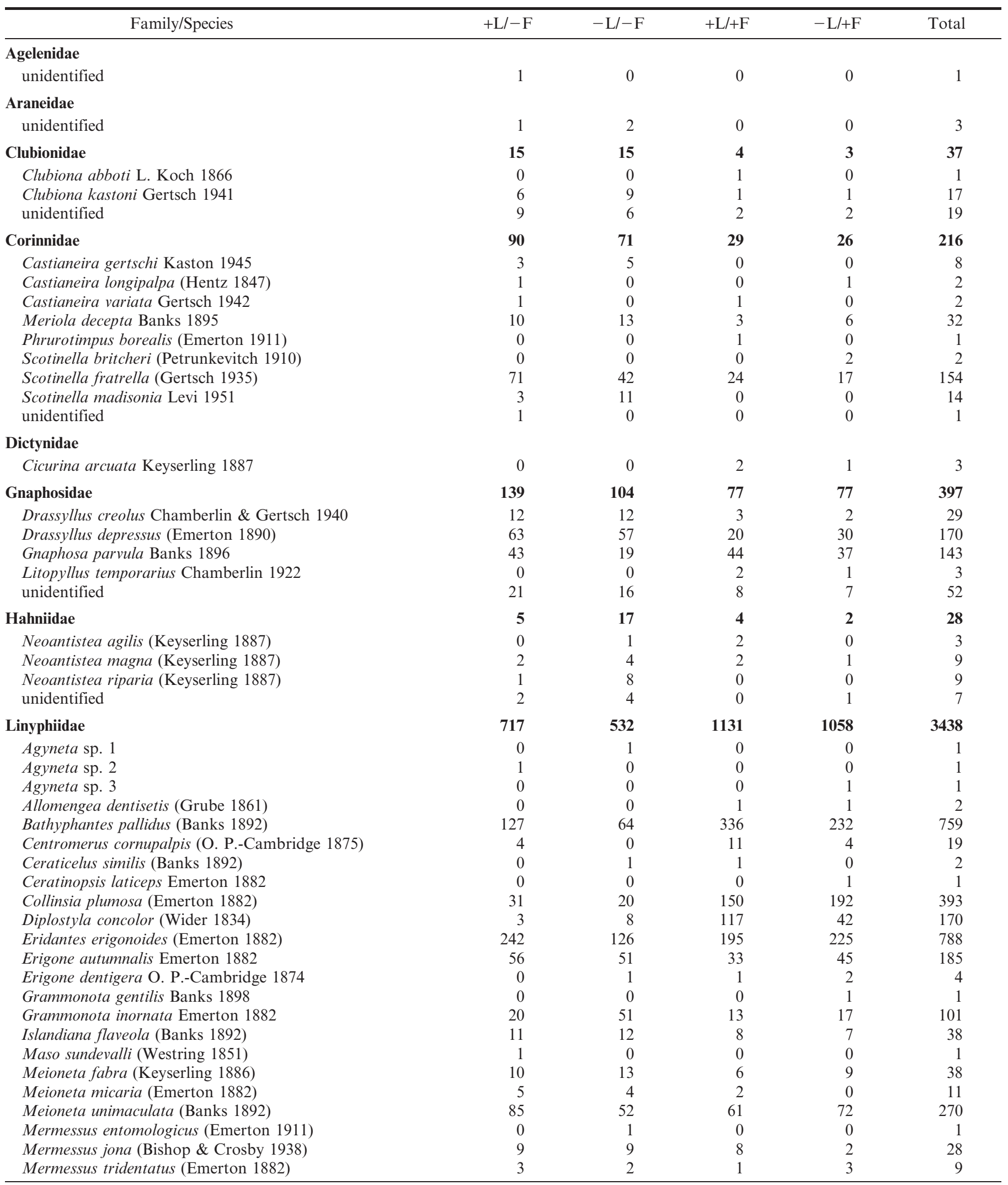


Table 1.-Continued.

\begin{tabular}{l} 
Family/Species \\
\hline Mermessus trilobatus (Emerton 1882) \\
Neriene clathrata (Sundevall 1830) \\
Oedothorax trilobatus (Banks 1896) \\
Tennesseellum formica (Emerton 1882) \\
Tenuiphantes tenuis (Blackwall 1852) \\
Walckenaeria directa (O. P.-Cambridge 1874) \\
Walckenaeria palustris Millidge 1983 \\
Walckenaeria sp. 1 \\
Walckenaeria sp. 2 \\
Walckenaeria spiralis (Emerton 1882) \\
Walckenaeria tibialis (Emerton 1882) \\
unidentified
\end{tabular}

\section{Liocranidae}

$\begin{array}{rr}+\mathrm{L} /-\mathrm{F} & -\mathrm{L} / \\ 38 & 26 \\ 23 & \\ 0 & \\ 0 & \\ 0 & \\ 3 & \\ 0 & \\ 1 & \\ 0 & \\ 12 & \\ 1 & \\ 31 & \end{array}$

$\begin{array}{rr}-\mathrm{L} /-\mathrm{F} & +\mathrm{L} /+\mathrm{F} \\ 26 & 55 \\ 8 & 2 \\ 0 & 2 \\ 1 & 0 \\ 0 & 0 \\ 0 & 6 \\ 0 & 1 \\ 0 & 0 \\ 0 & 1 \\ 28 & 30 \\ 0 & 0 \\ 53 & 90\end{array}$

\begin{tabular}{rrr}
\hline$/+F$ & $-\mathrm{L} /+\mathrm{F}$ & Total \\
55 & 56 & 175 \\
2 & 6 & 39 \\
2 & 5 & 7 \\
0 & 0 & 1 \\
0 & 5 & 5 \\
6 & 3 & 12 \\
1 & 0 & 1 \\
0 & 0 & 1 \\
1 & 0 & 1 \\
30 & 63 & 133 \\
0 & 0 & 1 \\
90 & 64 & 238
\end{tabular}

Agroeca pratensis Emerton 1890

\section{Lycosidae}

Allocosa funerea (Hentz 1844)

Hogna helluo (Walckenaer 1837)

Pardosa milvina (Hentz 1844)

Pardosa modica (Blackwall 1846)

Pardosa moesta Banks 1892

Pardosa saxatilis (Hentz 1844)

Pirata aspirans Chamberlin 1904

Pirata sedentarius Montgomery 1904

Piratula canadensis (Dondale \& Redner 1981)

Piratula gigantea (Gertsch 1934)

Piratula insularis (Emerton 1885)

Piratula minuta (Emerton 1885)

Rabidosa punctulata (Hentz1844)

Rabidosa rabida (Walckenaer 1837)

Schizocosa avida (Walckenaer 1837)

Schizocosa bilineata (Emerton 1885)

Schizocosa crassipalpata Roewer 1951

Trochosa ruricola (De Geer 1778)

Trochosa terricola Thorell 1856

Varacosa avara (Keyserling 1877)

unidentified

Philodromidae

Ebo latithorax Keyserling 1884

\section{Salticidae}

Ghelna barrowsi (Kaston 1873)

Ghelna canadensis (Banks 1897)

Ghelna castanea (Hentz 1846)

Marpissa lineata (C.L. Koch 1846)

Myrmarachne formicaria (De Geer 1778)

Neon avalonus Gertsch \& Ivie 1955

Neon nelli Peckham \& Peckham 1888

Neon plutonus Gertsch \& Ivie 1955

Sarinda hentzi (Banks 1913)

Talavera minuta (Banks 1895)

unidentified

$\begin{array}{rr}1 & \\ 1913 & 2021 \\ 19 & \\ 0 & \\ 0 & \\ 2 & \\ 344 & 233 \\ 140 & 132 \\ 0 & \\ 0 & \\ 0 & \\ 0 & \\ 7 & \\ 365 & \\ 2 & \\ 4 & \\ 33 & \\ 80 & \\ 113 & \\ 24 & \\ 18 & \\ 2 & \\ 760 & 64\end{array}$

0
$\mathbf{2 0 2 1}$
15
6
3
1
233
132
1
1
1
0
27
638
3
3
94
61
108
16
29
1
648

0
2422
2
1
0
6
1444
16
0
1
0
0
10
538
0
0
4
25
43
36
42
0
254

0
2276
14
1
0
3
1177
73
0
10
0
1
22
395
0
0
9
34
71
37
36
0
393

1

8632

50

8

3

12

3198

361

12

1

1

66
1936

5

7

140

200

335

113

125

3

2055

Tetragnathidae

Glenognatha foxi (McCook 1894)

Pachygnatha autumnalis Marx 1884

Pachygnatha clerki Sundevall 1823

Pachygnatha xanthostoma C.L. Koch 1845

Tetragnatha laboriosa Hentz 1850

unidentified

$\begin{array}{rrrrr}0 & 1 & 0 & 0 & 1 \\ \mathbf{6 3} & \mathbf{7 5} & \mathbf{1 6} & \mathbf{2 1} & \mathbf{1 7 5} \\ 1 & 2 & 0 & 1 & 4 \\ 4 & 3 & 0 & 2 & 9 \\ 2 & 0 & 0 & 0 & 2 \\ 7 & 3 & 1 & 2 & 13 \\ 0 & 1 & 0 & 1 & 2 \\ 1 & 0 & 0 & 0 & 1 \\ 7 & 12 & 1 & 2 & 22 \\ 25 & 35 & 7 & 7 & 74 \\ 0 & 1 & 0 & 0 & 1 \\ 11 & 7 & 2 & 3 & 23 \\ 5 & 11 & 5 & 3 & 24 \\ \mathbf{5 1} & \mathbf{4 6} & \mathbf{1 6} & \mathbf{2 2} & \mathbf{1 3 5} \\ 9 & 10 & 3 & 8 & 30 \\ 17 & 14 & 9 & 6 & 46 \\ 0 & 0 & 0 & 1 & 1 \\ 0 & 0 & 1 & 0 & 1 \\ 1 & 0 & 0 & 0 & 1 \\ 24 & 22 & 3 & 7 & 56\end{array}$


Table 1.-Continued.

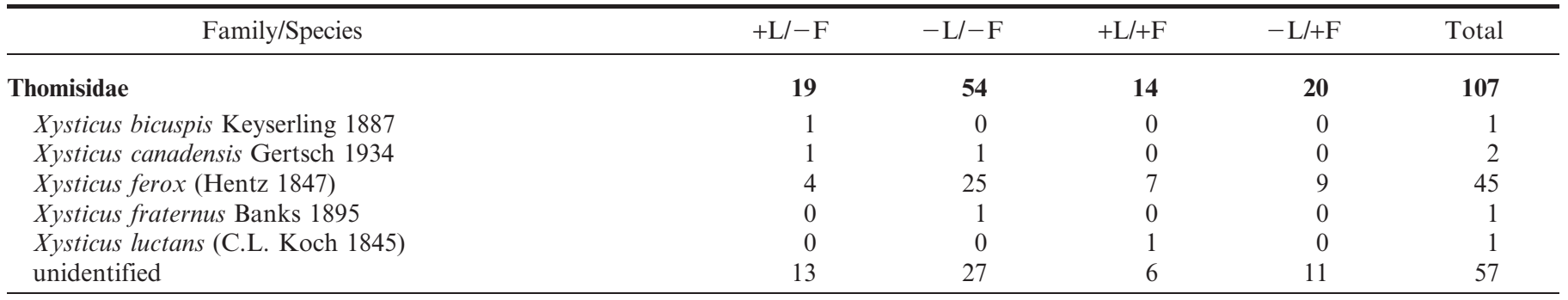

Spider species-level analyses.-The most abundant spider was Pardosa moesta Banks 1892, with 3198 mature specimens captured $(30.0 \%$ of all mature spiders, $48.6 \%$ of mature lycosids). Pardosa moesta was easily the most captured spider in fertilized plots although being virtually absent from unfertilized plots (Fig. 5A), and had a strong response to fertilization and year, resulting in a significant fertilization by year interaction (Table 3). A smaller lycosid, Piratula minuta (Emerton 1885), was the second most abundant spider with 1936 mature specimens captured $(18.2 \%$ of all mature spiders, $29.4 \%$ of mature lycosids) but did not seem to specifically and consistently respond to a particular treatment (Fig. 5B), though year and the fertilization by litter interaction were significant (Table 3). Together, these two species accounted for nearly half $(48.2 \%)$ of all mature spiders captured, and over three-quarters $(78 \%)$ of all mature lycosid spiders.

The third most abundant spider was the linyphiid Eridantes erigonoides (Emerton 1882), with 788 mature specimens captured $(7.4 \%$ of all mature spiders, $24.6 \%$ of mature linyphiid spiders). Similar to Pi. minuta, E. erigonoides did not consistently respond to any particular treatment (Fig. 5C), but did have a significant response to year in the repeatedmeasures analysis (Table 3). However, the fourth most abundant spider, the linyphiid Bathyphantes pallidus (Banks 1892) with 759 mature specimens captured $(7.1 \%$ of all mature spiders, $23.7 \%$ of linyphiid spiders), strongly responded to fertilization, year, and the interaction between fertilization and year, and responded marginally significantly to litter (Fig. 5D; Table 3). Virtually absent from the study site during the first two years of the study, B. pallidus became a fairly common spider in fertilized plots during the final two years of the study, with a weak affiliation to plots where litter was left in situ (Fig. 5D). Also virtually absent from the site during the first two years of the study, the fifth most abundant spider, the linyphiid Collinsia plumosa (Emerton 1882) with 393 specimens captured $(3.7 \%$ of all mature spiders, $12.3 \%$ of mature linyphiid spiders), also strongly responded to fertilization and year, which resulted in a significant interaction between fertilization and year (Fig. 5E; Table 3).

One of the most abundant of the larger spiders, the lycosid Schizocosa avida (Walckenaer 1837) with 140 mature specimens captured $(1.3 \%$ of all mature spiders, $2.1 \%$ of mature lycosid spiders), was virtually absent from fertilized plots (Fig. 5F). All variables were significant at the $\alpha<0.05$ level (Table 3). The species was most commonly captured in litterremoved treatments, particularly in unfertilized plots with litter removed $(-\mathrm{L} /-\mathrm{F})$.

Table 2.- Results of the GLMM for each response variable. Given are the $F$ values with degrees of freedom and the resulting $P$ values, where bolded values indicate significance at $\alpha<0.0007$ (after applying Bonferroni correction). The predictor variables are fertilization (F), litter (L), year (Y), and (*) their fully factorial interactions. Species richness is indicated by "SR."

\begin{tabular}{|c|c|c|c|c|c|c|c|}
\hline Response Variable & $\mathrm{F}$ & $\mathrm{L}$ & $\mathrm{Y}$ & $\mathrm{F}^{*} \mathrm{~L}$ & $\mathrm{~F}^{*} \mathrm{Y}$ & $\mathrm{L}^{*} \mathrm{Y}$ & $\mathrm{F}^{*} \mathrm{~L}^{*} \mathrm{Y}$ \\
\hline$\overline{e^{H^{\prime}}}$ & $\begin{aligned} F_{1,80} & =6.6 \\
P & =0.0124\end{aligned}$ & $\begin{aligned} F_{1,80} & =0.8 \\
P & =0.39\end{aligned}$ & $\begin{aligned} F_{3,80} & =80.0 \\
\boldsymbol{P} & <\mathbf{0 . 0 0 0 1}\end{aligned}$ & $\begin{aligned} F_{1,80} & =2.2 \\
P & =0.14\end{aligned}$ & $\begin{aligned} F_{3,80} & =1.4 \\
P & =0.25\end{aligned}$ & $\begin{aligned} F_{3,80} & =2.3 \\
P & =0.08\end{aligned}$ & $\begin{aligned} F_{3,80} & =0.2 \\
P & =0.89\end{aligned}$ \\
\hline Araneae SR & $\begin{aligned} F_{1,80} & =1.0 \\
P & =0.33\end{aligned}$ & $\begin{aligned} F_{1,80} & =0.5 \\
P & =0.48\end{aligned}$ & $\begin{aligned} F_{3,80} & =87.1 \\
\boldsymbol{P} & <\mathbf{0 . 0 0 0 1}\end{aligned}$ & $\begin{aligned} F_{1,80} & =1.5 \\
P & =0.23\end{aligned}$ & $\begin{aligned} F_{3,80} & =3.4 \\
P & =0.0231\end{aligned}$ & $\begin{aligned} F_{3,80} & =1.6 \\
P & =0.19\end{aligned}$ & $\begin{aligned} F_{3,80} & =0.3 \\
P & =0.84\end{aligned}$ \\
\hline Araneae abundance & $\begin{aligned} F_{1,80} & =39.64 \\
\boldsymbol{P} & <\mathbf{0 . 0 0 0 1}\end{aligned}$ & $\begin{aligned} F_{1,80} & =1.0 \\
P & =0.32\end{aligned}$ & $\begin{aligned} F_{3,80} & =54.9 \\
\boldsymbol{P} & <\mathbf{0 . 0 0 0 1}\end{aligned}$ & $\begin{aligned} F_{1,80} & =0.7 \\
P & =0.42\end{aligned}$ & $\begin{aligned} F_{3,80} & =5.2 \\
P & =0.0024\end{aligned}$ & $\begin{aligned} F_{3,80} & =0.1 \\
P & =0.98\end{aligned}$ & $\begin{aligned} F_{3,80} & =0.8 \\
P & =0.48\end{aligned}$ \\
\hline Araneae biomass & $\begin{aligned} F_{1,80} & =0.0 \\
P & =0.84\end{aligned}$ & $\begin{aligned} F_{1,80} & =1.6 \\
P & =0.21\end{aligned}$ & $\begin{aligned} F_{3,80} & =38.1 \\
\boldsymbol{P} & <\mathbf{0 . 0 0 0 1}\end{aligned}$ & $\begin{aligned} F_{1,80} & =2.3 \\
P & =0.14\end{aligned}$ & $\begin{aligned} F_{3,80} & =1.5 \\
P & =0.23\end{aligned}$ & $\begin{aligned} F_{3,80} & =1.6 \\
P & =0.19\end{aligned}$ & $\begin{aligned} F_{3,80} & =2.0 \\
P & =0.12\end{aligned}$ \\
\hline Linyphiidae SR & $\begin{aligned} F_{1,80} & =28.1 \\
\boldsymbol{P} & <\mathbf{0 . 0 0 0 1}\end{aligned}$ & $\begin{aligned} F_{1,80} & =0.2 \\
P & =0.66\end{aligned}$ & $\begin{aligned} F_{3,80} & =53.1 \\
\boldsymbol{P} & <\mathbf{0 . 0 0 0 1}\end{aligned}$ & $\begin{aligned} F_{1,80} & =2.8 \\
P & =0.10\end{aligned}$ & $\begin{aligned} F_{3,80} & =9.7 \\
\boldsymbol{P} & <\mathbf{0 . 0 0 0 1}\end{aligned}$ & $\begin{aligned} F_{3,80} & =1.9 \\
P & =0.14\end{aligned}$ & $\begin{aligned} F_{3,80} & =0.4 \\
P & =0.76\end{aligned}$ \\
\hline Linyphiidae abundance & $\begin{aligned} F_{1,80} & =20.9 \\
\boldsymbol{P} & <\mathbf{0 . 0 0 0 1}\end{aligned}$ & $\begin{aligned} F_{1,80} & =1.5 \\
P & =0.22\end{aligned}$ & $\begin{aligned} F_{3,80} & =17.3 \\
\boldsymbol{P} & <\mathbf{0 . 0 0 0 1}\end{aligned}$ & $\begin{aligned} F_{1,80} & =0.7 \\
P & =0.40\end{aligned}$ & $\begin{aligned} F_{3,80} & =6.6 \\
\boldsymbol{P} & =\mathbf{0 . 0 0 0 5}\end{aligned}$ & $\begin{aligned} F_{3,80} & =0.1 \\
P & =0.97\end{aligned}$ & $\begin{aligned} F_{3,80} & =0.2 \\
P & =0.87\end{aligned}$ \\
\hline Linyphiidae biomass & $\begin{aligned} F_{1,80} & =24.2 \\
\boldsymbol{P} & <\mathbf{0 . 0 0 0 1}\end{aligned}$ & $\begin{aligned} F_{1,80} & =3.5 \\
P & =0.07\end{aligned}$ & $\begin{aligned} F_{3,80} & =27.1 \\
\boldsymbol{P} & <\mathbf{0 . 0 0 0 1}\end{aligned}$ & $\begin{aligned} F_{1,80} & =0.00 \\
P & =0.95\end{aligned}$ & $\begin{aligned} F_{3,80} & =6.7 \\
\boldsymbol{P} & =\mathbf{0 . 0 0 0 4}\end{aligned}$ & $\begin{aligned} F_{3,80} & =1.5 \\
P & =0.22\end{aligned}$ & $\begin{aligned} F_{3,80} & =0.3 \\
P & =0.83\end{aligned}$ \\
\hline Lycosidae SR & $\begin{aligned} F_{1,80} & =5.4 \\
P & =0.0223\end{aligned}$ & $\begin{aligned} F_{1,80} & =1.9 \\
P & =0.17\end{aligned}$ & $\begin{aligned} F_{3,80} & =86.8 \\
\boldsymbol{P} & <\mathbf{0 . 0 0 0 1}\end{aligned}$ & $\begin{aligned} F_{1,80} & =0.2 \\
P & =0.69\end{aligned}$ & $\begin{aligned} F_{3,80} & =1.1 \\
P & =0.35\end{aligned}$ & $\begin{aligned} F_{3,80} & =0.6 \\
P & =0.65\end{aligned}$ & $\begin{aligned} F_{3,80} & =0.4 \\
P & =0.75\end{aligned}$ \\
\hline Lycosidae abundance & $\begin{aligned} F_{1,} 80 & =22.8 \\
P & <\mathbf{0 . 0 0 0 1}\end{aligned}$ & $\begin{aligned} F_{1,80} & =0.1 \\
P & =0.82\end{aligned}$ & $\begin{aligned} F_{3,80} & =29.1 \\
\boldsymbol{P} & <\mathbf{0 . 0 0 0 1}\end{aligned}$ & $\begin{aligned} F_{1,80} & =2.1 \\
P & =0.15\end{aligned}$ & $\begin{aligned} F_{3,80} & =0.9 \\
P & =0.45\end{aligned}$ & $\begin{aligned} F_{3,80} & =0.0 \\
P & =0.9989\end{aligned}$ & $\begin{aligned} F_{3,80} & =0.4 \\
P & =0.77\end{aligned}$ \\
\hline Lycosidae biomass & $\begin{aligned} F_{1,80} & =0.0 \\
P & =0.85\end{aligned}$ & $\begin{aligned} F_{1,80} & =1.6 \\
P & =0.21\end{aligned}$ & $\begin{aligned} F_{3,80} & =31.5 \\
\boldsymbol{P} & <\mathbf{0 . 0 0 0 1}\end{aligned}$ & $\begin{aligned} F_{1,80} & =2.2 \\
P & =0.14\end{aligned}$ & $\begin{aligned} F_{3,80} & =1.6 \\
P & =0.20\end{aligned}$ & $\begin{aligned} F_{3,80} & =1.5 \\
P & =0.21\end{aligned}$ & $\begin{aligned} F_{3,80} & =1.8 \\
P & =0.15\end{aligned}$ \\
\hline
\end{tabular}




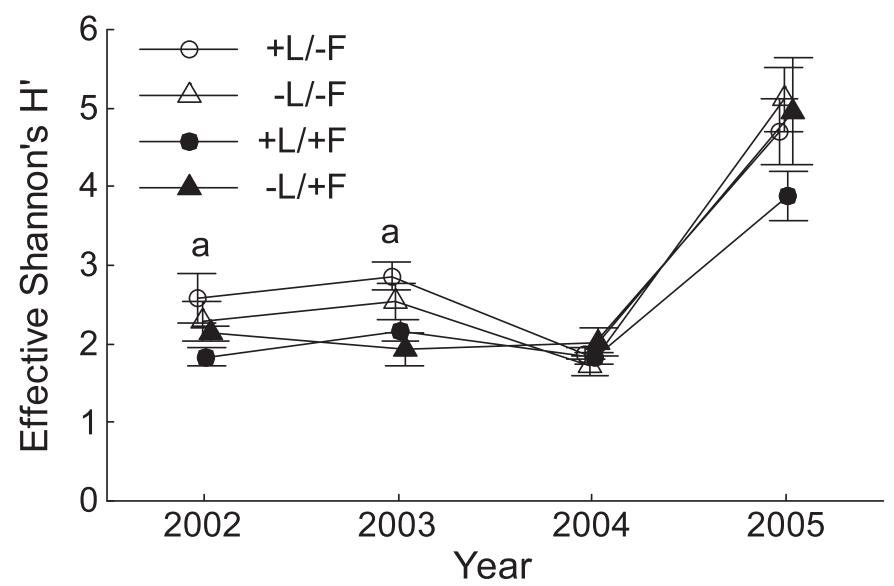

Figure 1.-Average effective Shannon's $\mathrm{H}^{\prime}\left(e^{H^{\prime}}\right)$ of spider species in each treatment; the letter "a" above a year denotes significance at $\alpha<0.05$ for fertilization. Open circles $(\bigcirc)$ and " $+\mathrm{L} /-\mathrm{F}$ " represent the control treatment plots of unfertilized and litter left in situ, open triangles $(\Delta)$ and " $-\mathrm{L} /-\mathrm{F}$ " represent unfertilized and litter removed plots, filled circles $(\mathbf{)})$ and " $+\mathrm{L} /+\mathrm{F}$ " represent fertilized and litter left in situ plots, and filled triangles $(\boldsymbol{\Delta})$ and " $-\mathrm{L} /+\mathrm{F}$ " represent fertilized and litter removed plots.

Aggregate ecosystem-level analyses. - The NMS ordination with Araneae species richness showed clustering of plots into treatments (Fig. 6A), and the ordination axes explained $78.9 \%$ of the variance, with the first axis explaining $44.8 \%$ of the variance, and the second axis explaining $34.1 \%$ of the variance. The final stress $=6.23$ with a final instability $=$ 0.099 , and results of the Monte Carlo simulation indicated that this stress was less than expected by chance $(P=0.001)$. Following Clarke (1993), a final stress between 5 and 10 was a very good ordination and did not present any real risk of misinterpretation. The first axis separated fertilized and unfertilized plots with high correlations to PAR $(r=$ $-0.912)$ and soil moisture $(r=-0.612)$ in the direction of unfertilized plots, and correlations to species richness $(r=$ $0.347)$ and percent soil organic content $(r=0.446)$ in the direction of fertilized plots, while plant litter biomass was not well correlated $(r=-0.127)$. The second axis separated litter removed from litter left in situ plots with a strong correlation to plant litter biomass $(r=0.916)$ in the direction of litter left in situ plots and PAR $(r=-0.529)$ in the direction of litter removed plots, but only weak or no correlations to the other three variables: spider species richness $r=-0.230$, percent soil moisture $r=-0.144$ and percent soil organic content $r=$ -0.034 .

Although the NMS ordination with Lycosidae did not produce a stable result, the NMS ordination with Linyphiidae species richness showed clustering of plots into treatments (Fig. 6B), and the ordination axes explained $92.9 \%$ of the variance, with the first axis explaining $71.7 \%$ of the variance and the second axis explaining $21.2 \%$ of the variance. The final stress $=8.89$ with a final instability $=0.056$, and results of the Monte Carlo simulation indicated that this stress was less than expected by chance $(P=0.002)$. The first axis separated fertilized and unfertilized plots with high correlations to PAR $(r=-0.953)$ and soil moisture $(r=-0.491)$ in the direction of unfertilized plots, and correlations to linyphiid species richness $(r=0.815)$ and percent soil organic content $(r=0.466)$ in the direction of fertilized plots, while plant litter biomass was not well correlated $(r=0.183)$. The second axis separated litter removed from litter left in situ plots with a strong correlation to plant litter biomass $(r=0.942)$ in the direction of litter left in situ plots and weakly correlated to linyphiid species richness $(r=-0.359)$ and percent soil organic content $(r=-0.297)$ in the direction of litter removed plots, and no correlations to the other two variables: PAR $r=$ -0.039 and percent soil moisture $r=-0.034$.

For both NMS ordinations, the separation of plots into treatment clusters was supported by MRPP (Table 4). When all four treatments were run together, the null hypothesis of no difference between treatments was rejected, with high withingroup agreement and very strong separation between groups. Pairwise comparisons of treatments showed that fertilized plots, while still significantly distinct, were more similar to each other than fertilized treatment plots were to any of the unfertilized treatment plots. The same pattern existed for unfertilized plots, with strong separation of unfertilized plots, yet with lower dissimilarity than when unfertilized plots were compared to fertilized plots. As expected, the maximal differences occurred when extremes of treatments were paired, as in $-\mathrm{L} /-\mathrm{F}$ vs. $+\mathrm{L} /+\mathrm{F}$, and $+\mathrm{L} /-\mathrm{F}$ vs. $-\mathrm{L} /+\mathrm{F}$, indicating that "opposite" treatments significantly alter biotic and abiotic components of the local habitat.

Table 3.- Results of the GLMM for six species. Given are the $F$ values with degrees of freedom, and the resulting $P$ values, where bolded values indicate significance at $\alpha<0.0012$ (after Bonferroni correction). The predictor variables are fertilization (F), litter (L), year (Y), and (*) their fully factorial interactions.

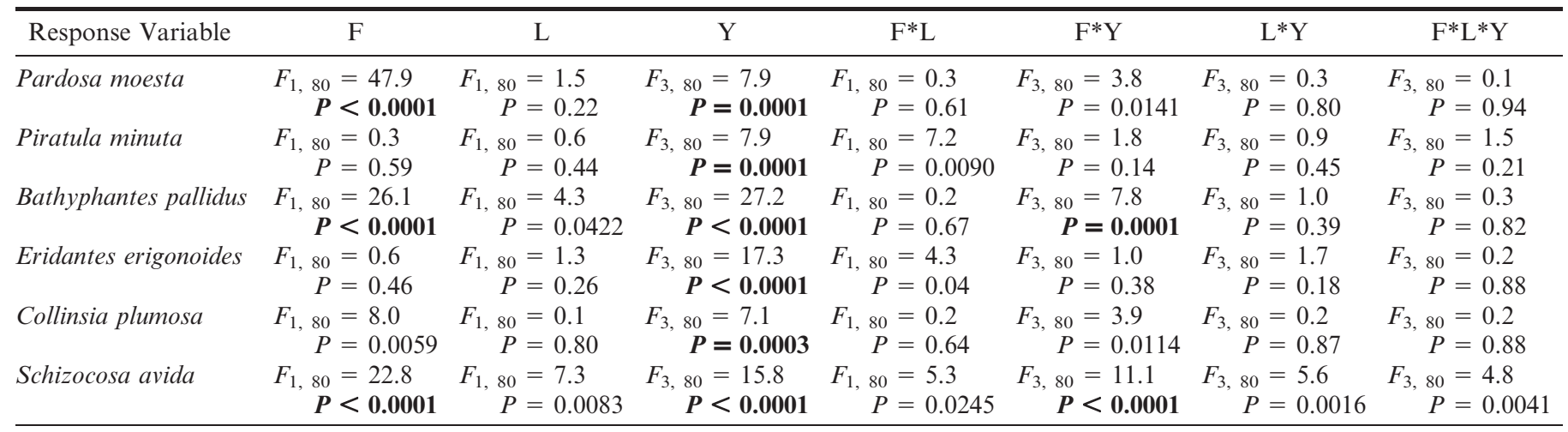


A.

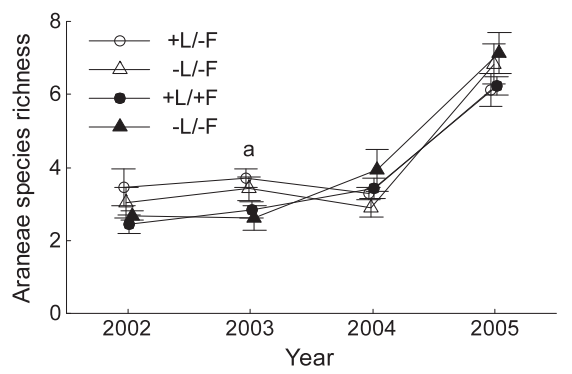

D.

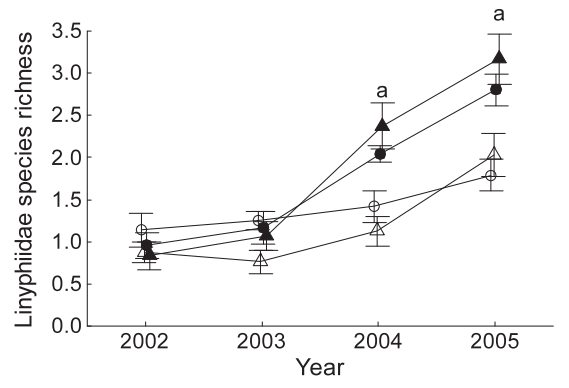

G.

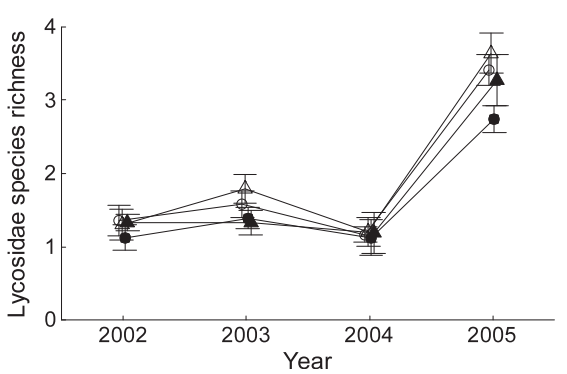

B.

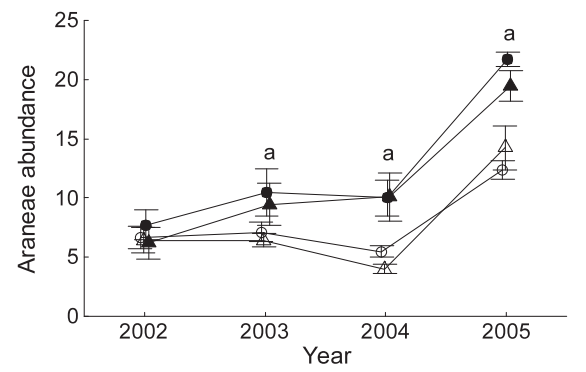

E.

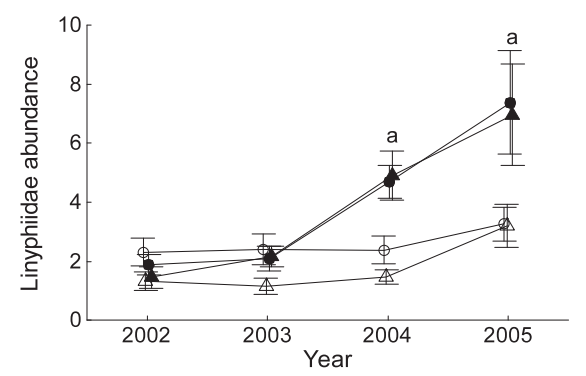

H.

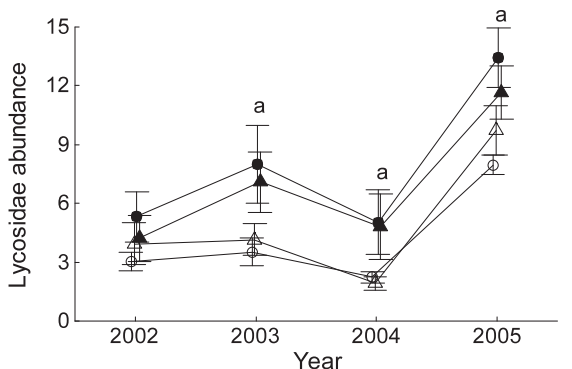

C.

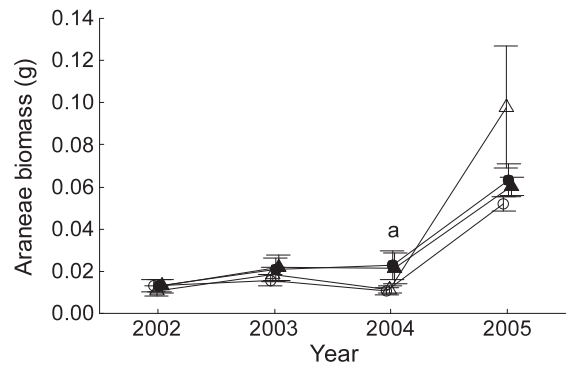

F.

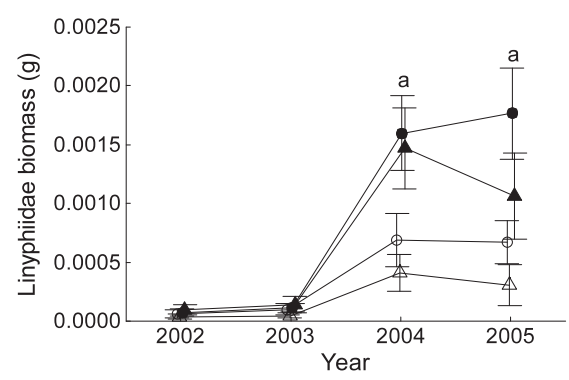

I.

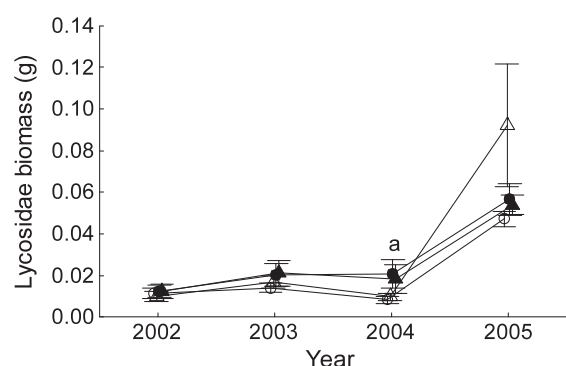

Figure 2.- Species richness, abundance, and biomass of all spiders (A-C), linyphiids (D-F), and lycosids (G-I). Definitions of symbols and abbreviations for treatments are given in Figure 1, while the letter "a" above a year denotes significance at $\alpha<0.05$ for fertilization.

\section{DISCUSSION}

Spider abundance increased as a result of fertilization, but neither spider biomass nor spider species richness was significantly affected, and therefore our first hypothesis was not supported. This result is contrary to previous studies in which arthropod diversity in fertilized plots decreased as abundance increased (e.g., Knops et al. 1999; Haddad et al. 2000, 2001). However, our null result for the overall spider community likely resulted from of a canceling effect of the responses of the two dominant spider families, the wolf spiders (Lycosidae) and the linyphiid spiders (Linyphiidae). Wolf spider abundance was indeed significantly affected by fertilization, but wolf spider biomass and species richness were not affected. As nearly two-thirds of all spiders captured were wolf spiders, the response of this family drove the patterns found in the overall spider data, though it should be noted that our pitfall trap sampling method may have more bias towards wolf spiders due to their cursorial habit.

On the other hand, fertilization increased the abundance, biomass, and species richness of linyphiid spiders during the final two years of the study. The species richness response was completely opposite of the predictions of biodiversity-productivity theory (Haddad et al. 2000, 2001; Suding et al. 2005). This was likely a result of a bottom-up food web response to fertilization by the main linyphiid spider food source, collembolans (Harwood et al. 2001; Romero \& Harwood 2010). Collembolans did not respond to the treatments despite the increased abundance of plant litter (L. B. Patrick, unpublished data), with the basal resource for the collembolan prey being the bacteria that aid in the breakdown of plant litter. Thus, while the basal resource likely increased, the primary consumer of that resource, collembolans, did not, but 
A.

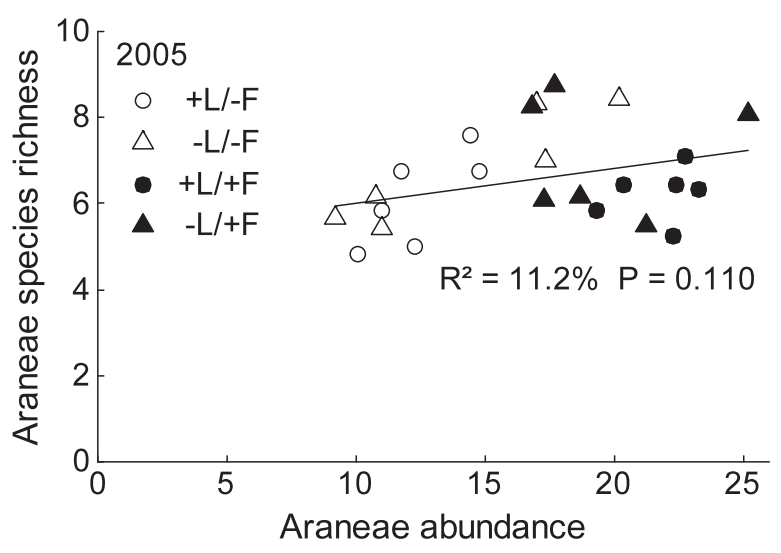

C.

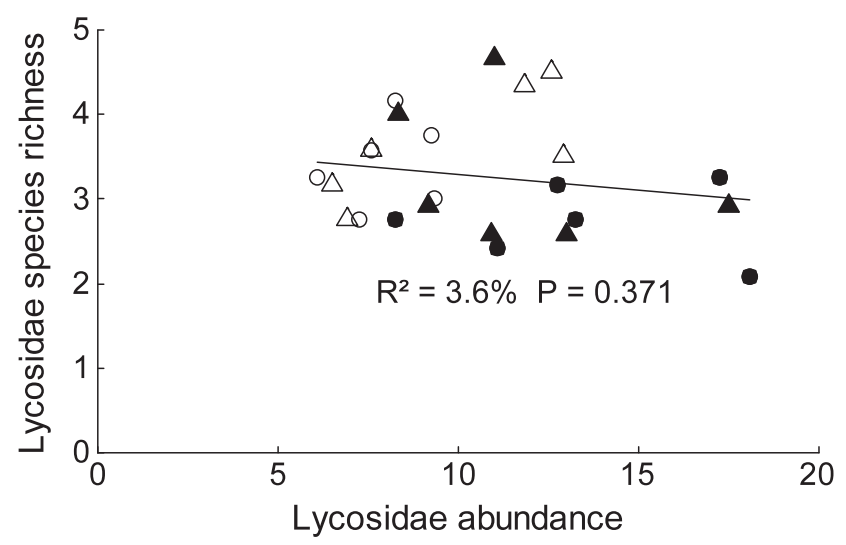

E.

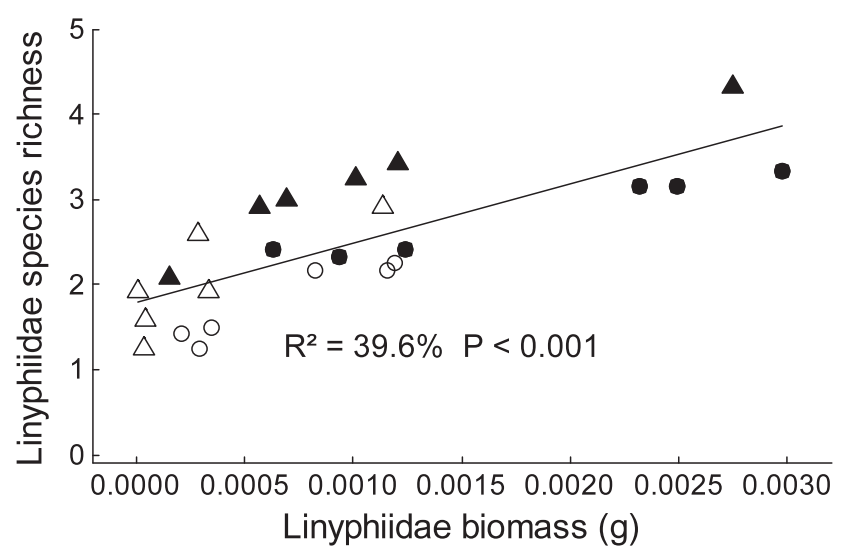

B.

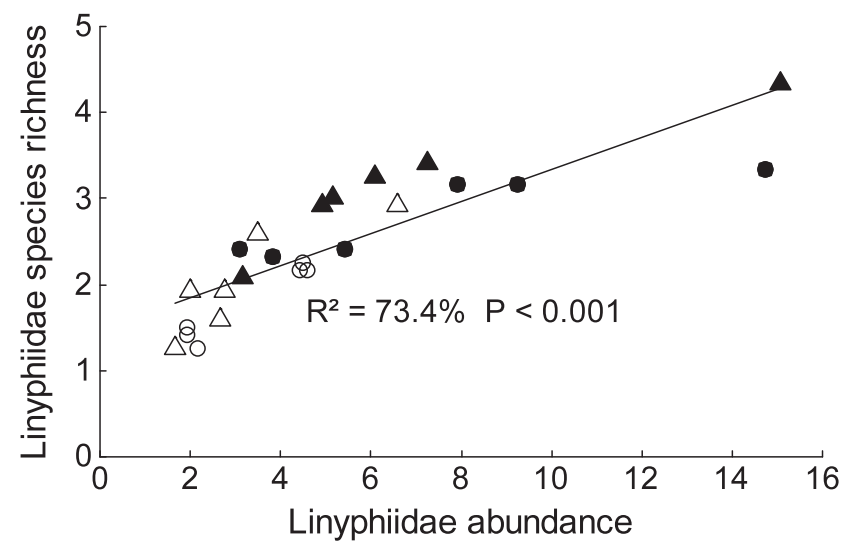

D.

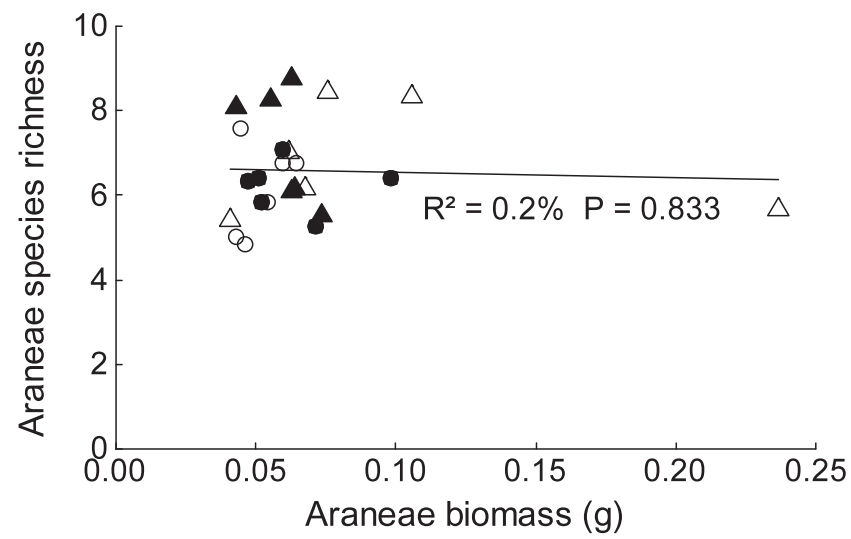

F.

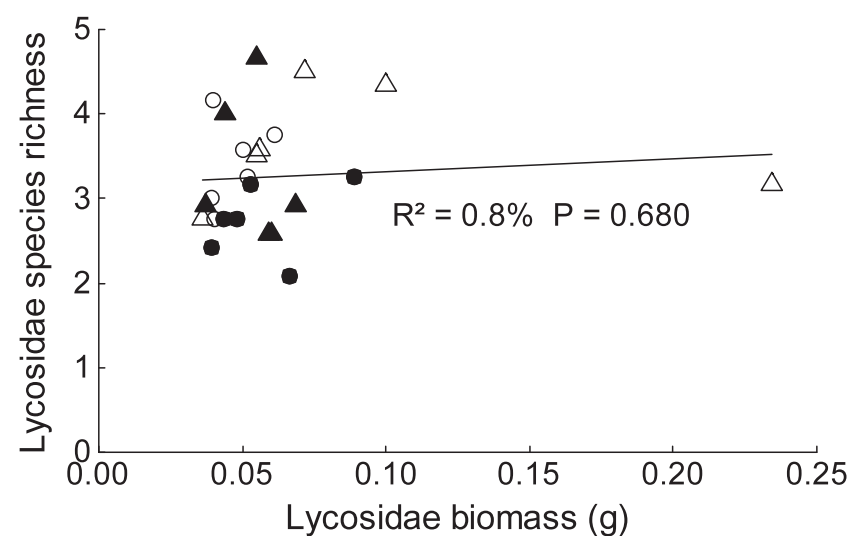

Figure 3.- Regressions of all spiders, linyphiids, and lycosids (left to right) against abundance (A-C) and biomass (D-F). Symbols are defined in Figure 1, and data presented are for 2005. 
A.

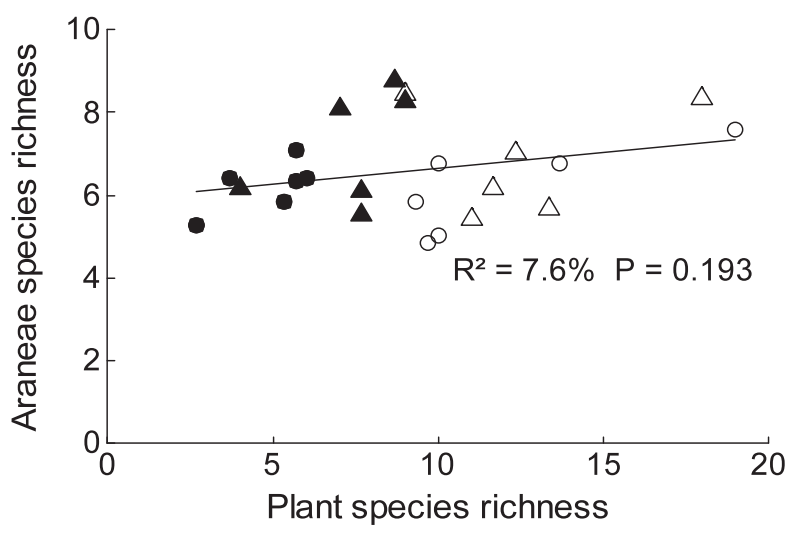

C.

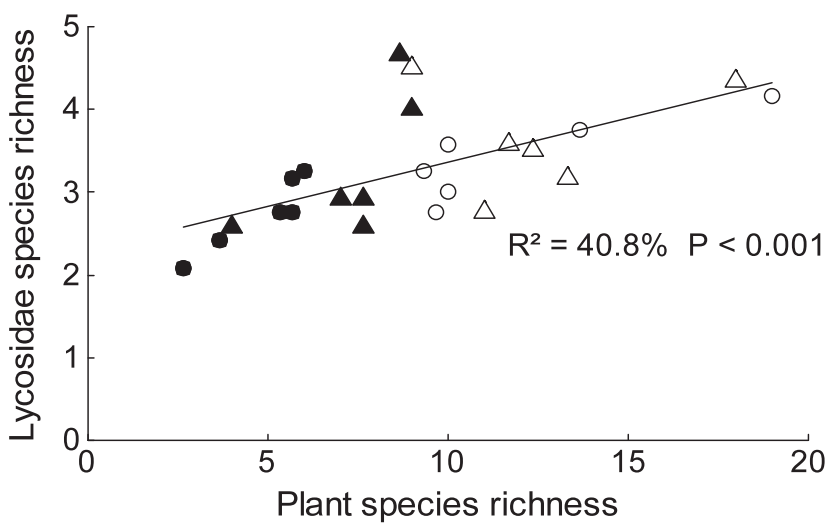

E.

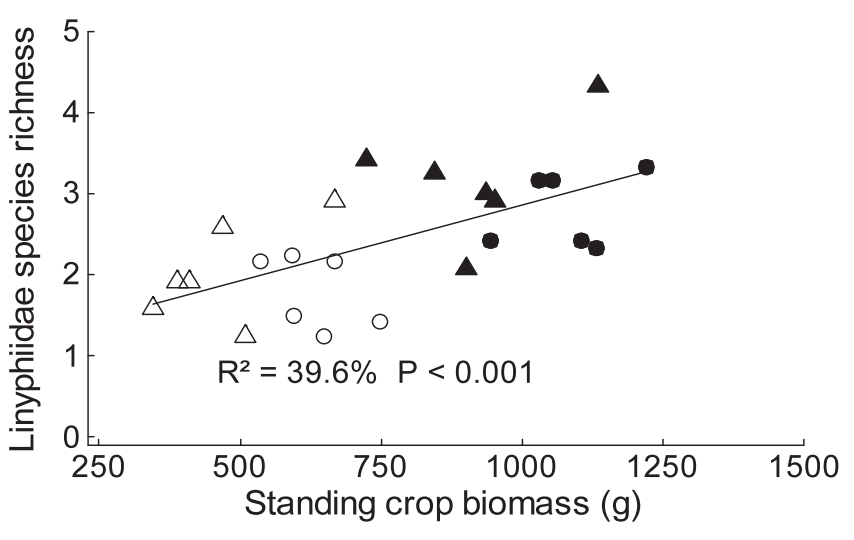

B.

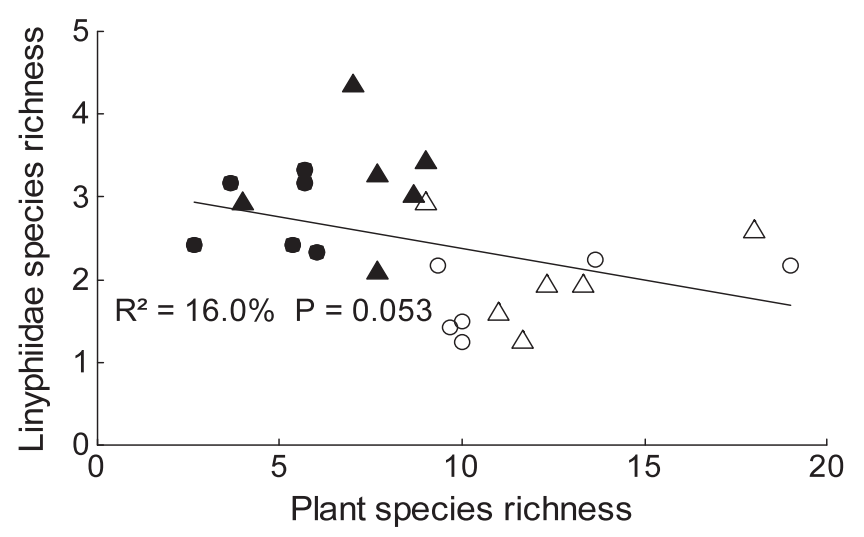

D.

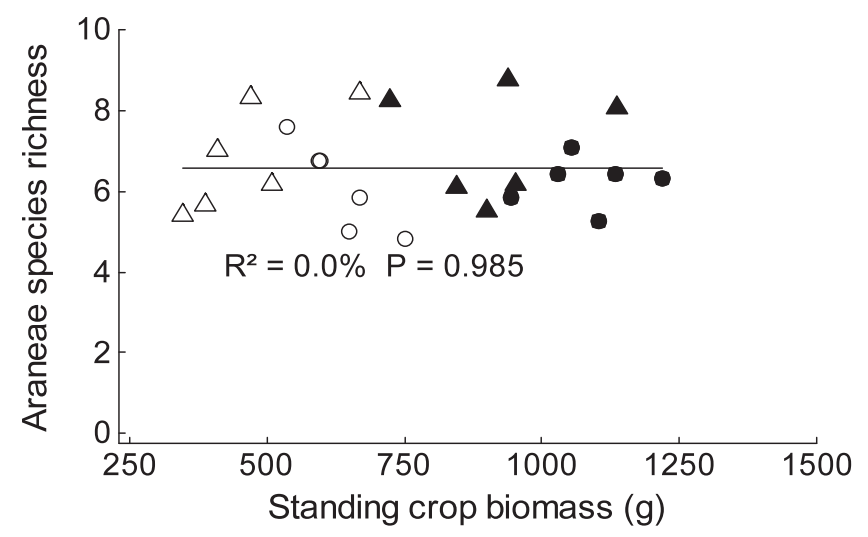

F.

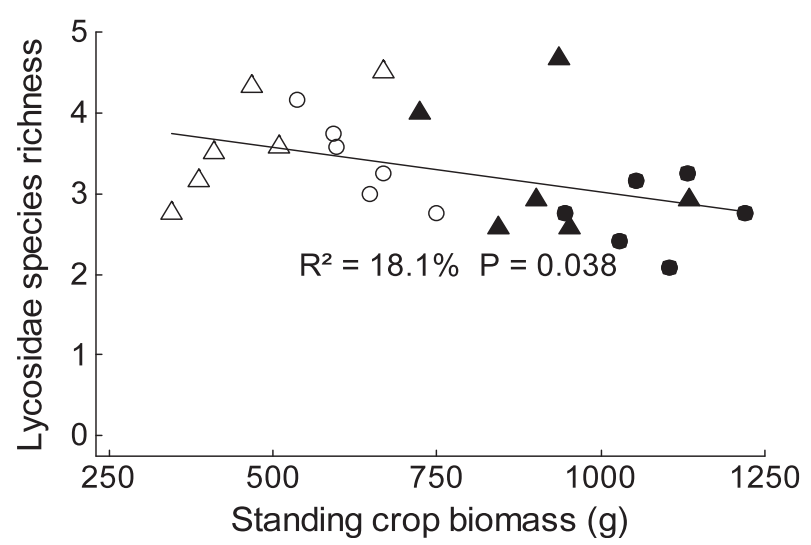

Figure 4.--Regressions of all spiders, linyphiids, and lycosids (left to right) against plant species richness (A-C) and standing crop biomass (D-F). Symbols are defined in Figure 1, and data presented are for 2005.

the primary collembolan predator did increase in abundance and diversity. It is therefore feasible to propose that a top-down food web effect by linyphiid spiders limited collembolan abundance, ultimately enhancing their own abundance and diversity.

The differences in responses between wolf and linyphiid spiders are likely the results of different foraging behaviors.
Spider guilds are based primarily on foraging behavior, habitat preferences and web type (Uetz et al. 1999). Based upon this classification system, wolf spiders are considered ground-running spiders, and linyphiid spiders are characterized as wandering sheet/tangle web weavers. Wolf spiders are classic epigeal wandering spiders that actively hunt for prey 
A. Pardosa moesta

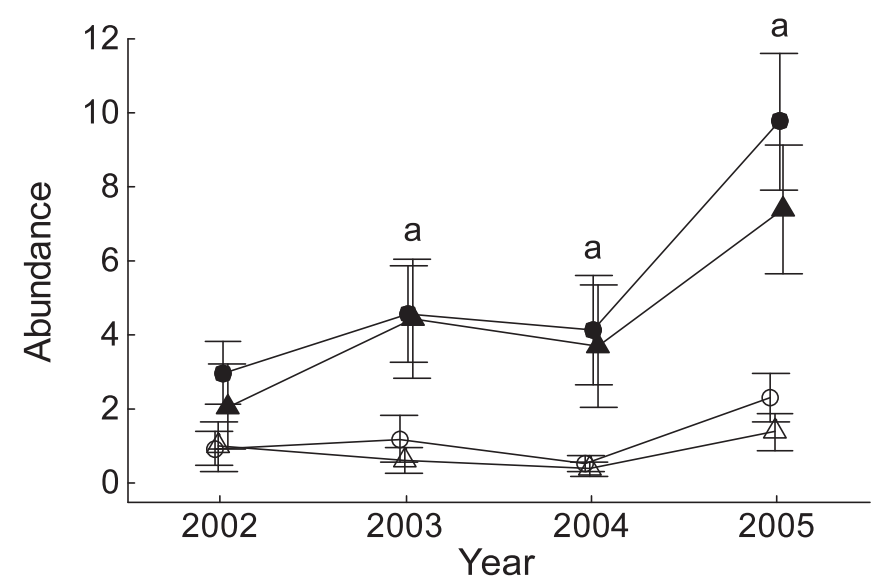

C. Eridantes erigonoides

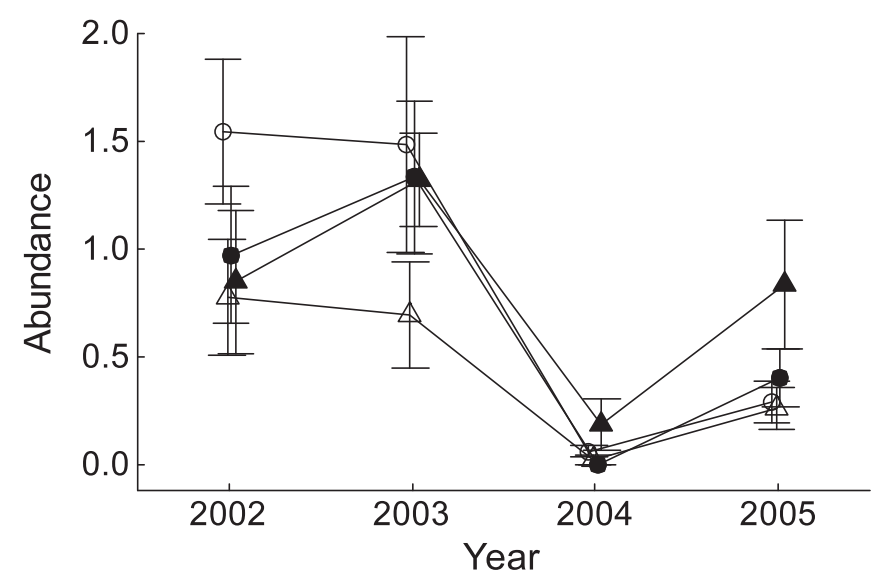

E. Collinsia plumosa

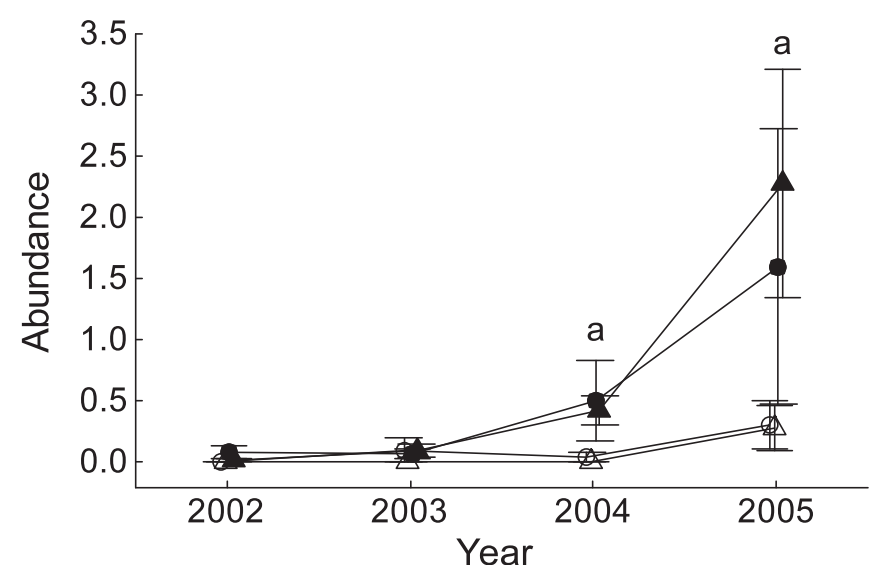

B. Piratula minuta

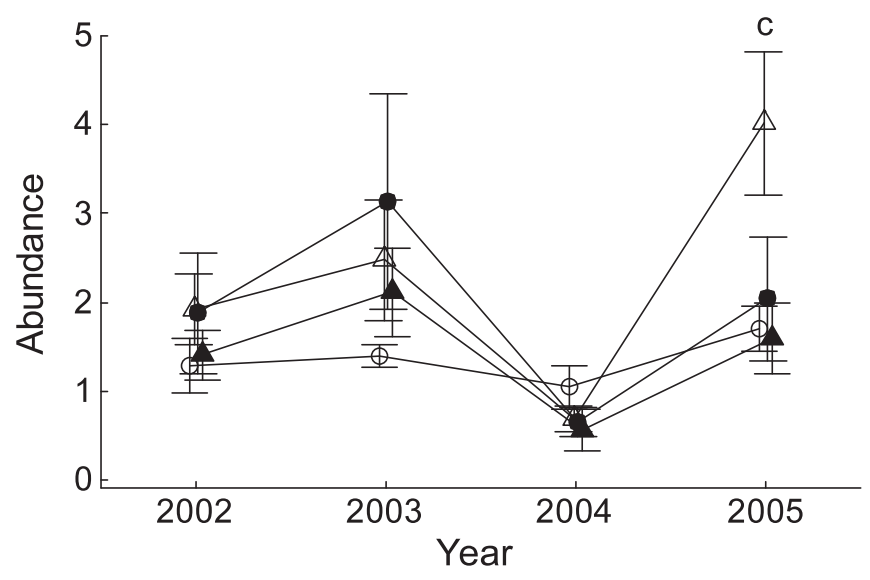

D. Bathyphantes pallidus

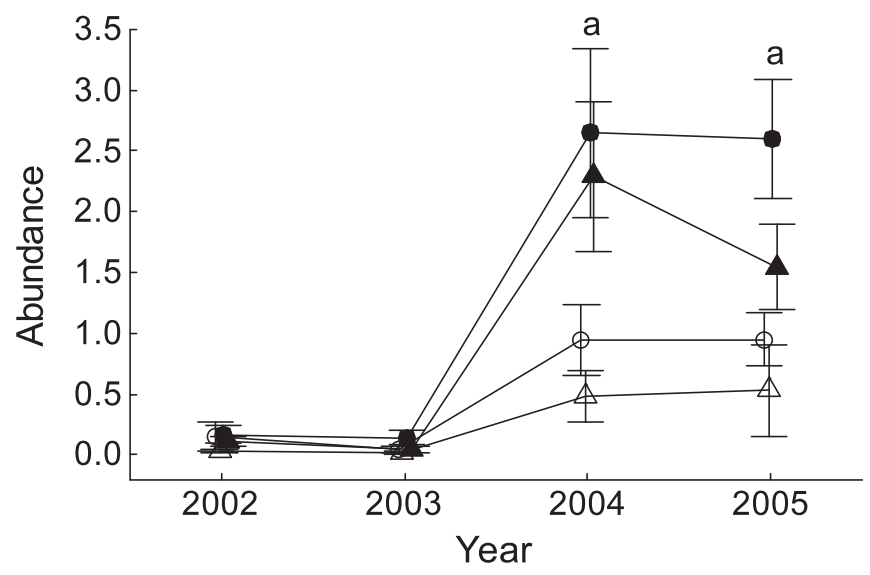

F. Schizocosa avida

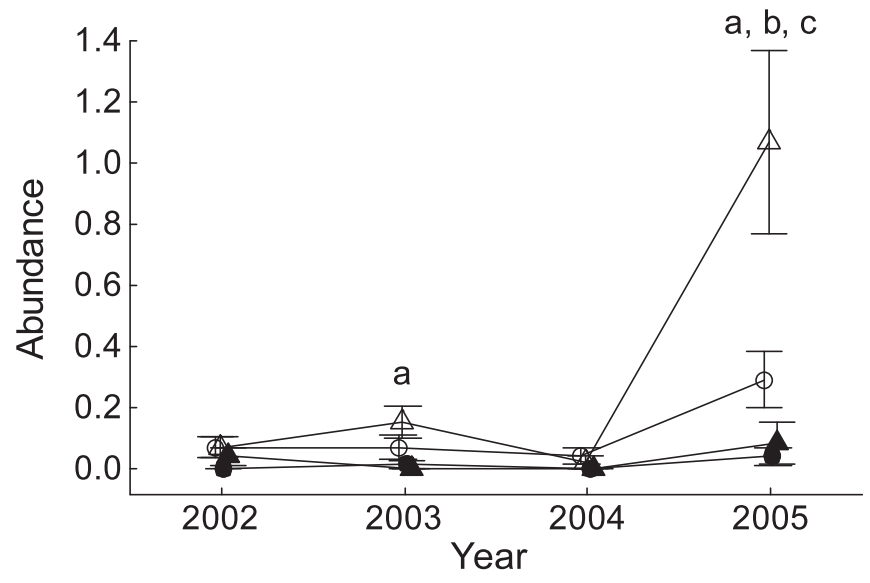

Figure 5.-Average abundance of selected species by year. Definitions of symbols and abbreviations for treatments are given in Figure 1, while the letters above each year denote significance at $\alpha<0.05$ for "a" = fertilization, "b" = litter, and "c" = the interaction of fertilization and litter. 


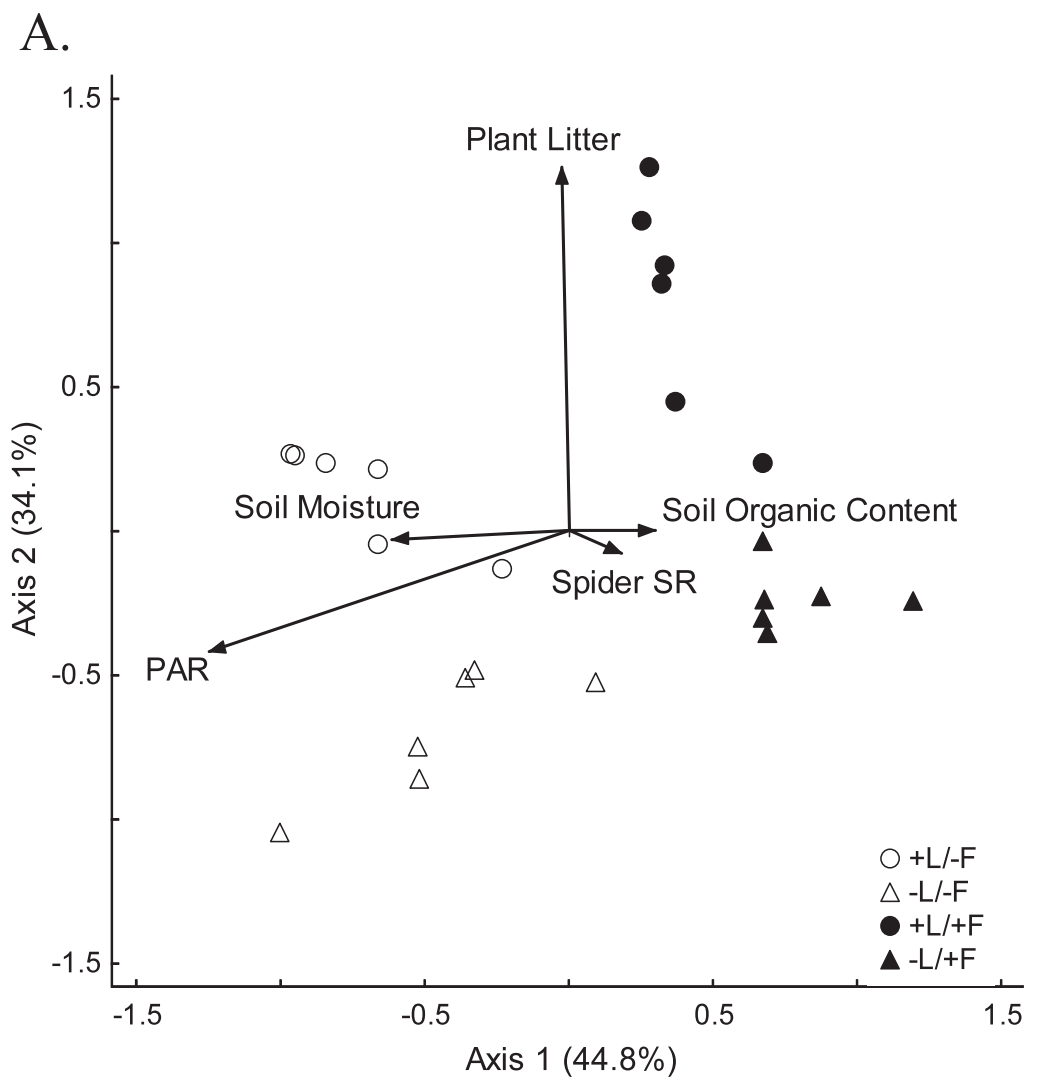

B.

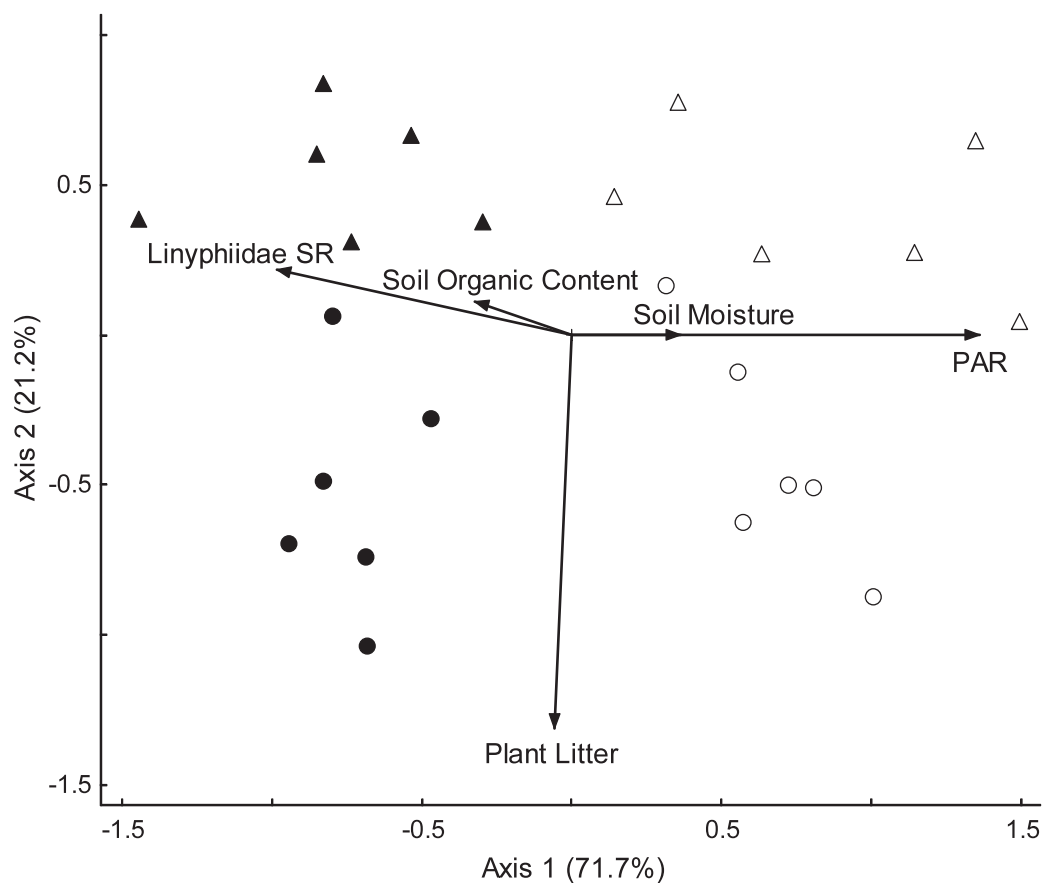

Figure 6.-Two-dimensional ordination of ecosystem-level properties from 2005 from nonmetric multidimensional scaling (NMS) using plant litter biomass, PAR, percent soil moisture, percent soil organic content, and (A) Araneae species richness or (B) Linyphiidae species richness (Lycosidae did not produce a stable result). Vectors indicate the direction and strength of correlations between axis scores and emergent properties $\left(R^{2}\right.$ cutoff for joint biplot $\left.=0.100\right)$, and ordinations are rotated to the dominant axis of fertilization. The percent of variance explained by each axis is noted next to the axis title. See Figure 1 for key to treatment symbols. 
Table 4.- Results of Multi-response Permutation Procedure (MRPP) on emergent properties for 2005 to support NMS analyses (Fig. 5). $T$ describes the separation between groups (dissimilarity), and $A$ is the chance-corrected within-group agreement. "All" indicates all four treatments included in the MRPP, and the remainders are MRPP pairwise comparisons of treatments to assess dissimilarity (lower $T$ and higher $A$ ). $+\mathrm{L}$ indicates litter left in situ, $-\mathrm{L}$ indicates litter removed, $+\mathrm{F}$ indicates fertilization, $-\mathrm{F}$ indicates no fertilization.

\begin{tabular}{lccr}
\hline \multicolumn{1}{c}{ Groups } & $T$ & $A$ & \multicolumn{1}{c}{$P$} \\
\hline All Spiders & & & \\
All & -9.892 & 0.421 & $<0.0001$ \\
+L/-F vs. $-\mathrm{L} /-\mathrm{F}$ & -3.352 & 0.164 & 0.0097 \\
+L/-F vs. $+\mathrm{L} /+\mathrm{F}$ & -5.838 & 0.332 & 0.0006 \\
+ $\mathrm{L} /-\mathrm{F}$ vs. $-\mathrm{L} /+\mathrm{F}$ & -6.014 & 0.414 & 0.0010 \\
- $\mathrm{L} /-\mathrm{F}$ vs. $+\mathrm{L} /+\mathrm{F}$ & -6.470 & 0.424 & 0.0006 \\
- $\mathrm{L} /-\mathrm{F}$ vs. $-\mathrm{L} /+\mathrm{F}$ & -5.643 & 0.313 & 0.0009 \\
+L/+F vs. $-\mathrm{L} /+\mathrm{F}$ & -4.999 & 0.313 & 0.0023 \\
Linyphiidae & & & \\
All & -10.055 & 0.437 & $<0.0001$ \\
+L/-F vs. $-\mathrm{L} /-\mathrm{F}$ & -3.236 & 0.159 & 0.0102 \\
+L/-F vs. $+\mathrm{L} /+\mathrm{F}$ & -6.395 & 0.373 & 0.0005 \\
+L/-F vs. $-\mathrm{L} /+\mathrm{F}$ & -6.445 & 0.442 & 0.0008 \\
- $\mathrm{L} /-\mathrm{F}$ vs. $+\mathrm{L} /+\mathrm{F}$ & -6.501 & 0.435 & 0.0006 \\
- $\mathrm{L} /-\mathrm{F}$ vs. $-\mathrm{L} /+\mathrm{F}$ & -5.842 & 0.338 & 0.0010 \\
+L/+F vs. $-\mathrm{L} /+\mathrm{F}$ & -5.188 & 0.284 & 0.0022 \\
\hline
\end{tabular}

and are largely restricted to hunting in two-dimensional space. Thus, habitat structure (i.e., the physical structure of the surrounding environment, including plant litter and living plant material) may enhance wolf spider hunting success by providing additional hiding places for ambush hunting and for lairs (Rypstra et al. 1999; Halaj et al. 2000). However, too much habitat structure can also increase predation and intraguild predation risk through increased density responses to habitat structure while inhibiting movement (Wise 2006; Rypstra et al. 2007). These factors reduce both abundance and hunting success, thereby reducing the numbers of wolf spiders in an area. In our study, the increased habitat structure that resulted from fertilization seemed to moderately (but not significantly) reduce wolf spider species richness while increasing wolf spider abundance. However, this increased abundance was likely due to the population explosion in fertilized plots of the medium-sized wolf spider, $P$. moesta (see below).

Linyphiid spiders rely more upon webs for prey capture, sometimes maintaining and patrolling multiple webs (Uetz et al. 1999). Although these webs are generally constructed at or close to the ground level, the webs can enhance prey capture space to include a portion of a third dimension. Moreover, increased habitat structure can provide additional structure for web building (Rypstra et al. 1999). Thus, while fertilized plots significantly reduced wolf spider species richness, probably due to the enhanced habitat structure that impeded foraging ability, these plots may have provided the tiny web building linyphiid spiders the habitat structure to flourish because of the increased structure for web building and, thus, increased prey capture rates.

A medium-sized wolf spider, $P$. moesta thrived in fertilized plots probably due to decreased intraguild predation by larger wolf spiders (e.g., S. avida) that became less abundant in fertilized plots. Moreover, there was increased abundance of potential prey in fertilized plots (Patrick et al. 2008b). These two factors together likely released $P$. moesta from competition and predation, resulting in an increased abundance in fertilized plots. However, these microhabitat changes likely caused the decreased abundance of $S$. avida in fertilized plots, as the increased habitat structure likely impeded this species' foraging abilities. Piratula minuta was one of the smallest wolf spiders captured at our site, and could have benefited from the increased habitat structure in a similar way to $P$. moesta. Although it was the second most abundant spider captured during the course of our study, it did not significantly respond to a single habitat, except for unfertilized plots with litter removed during 2005. Interestingly, $P i$. minuta was observed on several occasions in the jaws of $P$. moesta and $S$. avida, making $P i$. minuta a victim of intraguild predation.

Spider species richness was not significantly correlated with either plant species richness or standing crop biomass. However, both dominant spider families responded to fertilization (by the fourth year of the study) in distinctly different ways. Wolf spiders followed predictions of current biodiversity-productivity theory, with decreased species richness associated with decreased plant species richness and increased standing crop biomass. Although fertilization increased wolf spider abundance, wolf spider species richness was correlated with plant species richness and therefore decreased as nutrient loading into the system increased.

Finally, despite documented effects of increased habitat structure on arthropod abundances and diversity (e.g., Lawton 1983; Halaj et al. 2000), particularly for spiders (e.g., Uetz 1991; Rypstra et al. 1999; Halaj et al. 2000), our results do not support our second hypothesis. Plant litter had no significant effect on spider species richness. Most studies of spider responses to plant litter have been conducted in plant monocultures in agroecosystems (e.g., Rypstra et al. 1999). These managed ecosystems tend to have much higher disturbance and more bare ground than would be expected from a grassland. Thus, increased refugia via plant litter additions to these agroecosystems would certainly provide more habitat than the existing bare ground, so it is perhaps not surprising that there have been stronger responses to plant litter in agroecosystems.

Analysis of the spider community and associated abiotic variables demonstrated strong treatment effects. These highly differentiated treatments are likely to have a strong effect on ecosystem properties (e.g., nutrient cycling, carbon sequestering), an effect likely to increase through time as the treatment plots further mature. Spiders have been shown to affect detritivore abundance (Wise et al. 1999), thereby indirectly altering nutrient cycling within the system (Chen \& Wise 1999). The results of our ordinations clearly showed that our plots responded to our treatments and that the spider community affected ecosystem-level processes. The long-term implications are unknown, but it is clear that the trajectories of each treatment are significantly different and may impact ecosystem function and services. To our knowledge, this is the first time that these biotic and abiotic factors have been coupled in a multivariate ordination to explicitly determine whether they can define discrete and distinct predator 
communities and their associated abiotic properties in the context of the biodiversity-productivity theory. Most previous work (e.g., Haddad et al. 2000, 2001) did not attempt to associate the invertebrate community with abiotic changes resulting from fertilization, and we know of no other studies that coupled fertilization and plant litter effects to test predictions of biodiversity-productivity theory.

The diversity and community structure of spiders and other arthropods are sensitive to plot size (Martinko et al. 2006). The large size of our experimental plots integrated important determinants of the within-plot plant communities, including spatial heterogeneity (De Boeck et al. 2006), leaching of nutrients from litter (Berendse 1998), local nutrient cycling (Hooper \& Vitousek 1998) and the translocation of nutrients within clumping and clonal plants (Hutchings \& Bradbury 1986), which are the primary growth forms of our dominant graminoids (Patrick et al. 2008a). These spatial factors are also important to epigeal spiders because of their vagility and their need to find suitable food; the larger plot sizes more realistically emulate natural habitat patches of varying quality and can support higher insect diversity (Martinko et al. 2006). Other studies that examined the effects of nutrient loading on arthropod communities had plot sizes ranging from $9 \mathrm{~m}^{2}$ $169 \mathrm{~m}^{2}$ (e.g., Knops et al. 1999; Haddad et al. 2001), making our experimental plots $\left(314 \mathrm{~m}^{2}\right)$ nearly twice as large-an important factor when considering the vagility of some spider species.

However, we realize that our study has some distinct differences when compared to previous work. Our use of an NPK fertilizer, as opposed to N-only fertilizer, is likely to have induced a stronger response to fertilization due to the added $\mathrm{P}$ and K. Nevertheless, our plant results (see Patrick et al. 2008a) were generally consistent with other plant studies that used NPK fertilizers (e.g., Carson \& Barrett 1988; Turkington et al. 2002) and N-only fertilizers (e.g., Haddad et al. 2000; Tilman et al. 2002), which allowed us to formulate our epigeal spider hypotheses on the same bases as previous studies that investigated the responses of arthropods to nutrient loading. Further, our running definition of litter (see Methods) includes the vegetation mown in the previous year and not removed from litter left in situ treatment plots, potentially altering the nutritional quality of the litter relative to naturally senesced vegetation, and the physical structure of the litter as it lay after mowing (e.g., Semmartin et al. 2004). Because the timing of mowing was determined by the local township, litter from the annual mowing accumulated earlier than might normally be expected for this region of the USA. However, were the mowing to stop, the site would very quickly yield to encroaching woody vegetation typical of early secondary succession.

Our study underscores the disjunct between conventional, plant-based biodiversity-productivity theory and the animal component of the food web, particularly epigeal predators. This portion of the food web is more closely associated with the quality of its basal resource (plant litter) than with the diversity of that resource (Cross et al. 2006; Seeber et al. 2008). This starkly contrasts with the more aerial portion of the food web that is more dependent on living plants, where specialist herbivores can be affected by plant diversity more than by plant quality. Ultimately, the loss of plant species with increased nutrient loading may result in the loss of arthropod herbivores and their specialist predators and parasites. However, the increases in diversity may be balanced by the epigeal community and its different resource base.

\section{ACKNOWLEDGMENTS}

We sincerely thank C.D. Dondale for his help with identifying spiders, particularly linyphiids, and for providing comments on an earlier version of this paper. We also thank S. Pekár, F. Samu, and an anonymous reviewer for helpful comments. LBP would like to especially thank C.D. Dondale for teaching him the subtleties of spider identification. We also thank a multitude of graduate and undergraduate students who helped in the field, and B. Andreas for help identifying plants. This study was partially funded by a CanaColl grant and two Kent State University travel grants to LBP, and by a University of Akron Research II Initiative grant to LHF.

\section{LITERATURE CITED}

Berendse, F. 1998. Effects of dominant plant species on soil during succession in nutrient-poor ecosystems. Biogeochemistry 42:73-88.

Carson, W.P. \& G.W. Barrett. 1988. Succession in old-field plant communities: effects of contrasting types of nutrient enrichment. Ecology 69:984-994.

Chalcraft, D.R., S.B. Cox, C. Clark, E.E. Cleland, K.N. Suding, E. Weiher \& D. Pennington. 2008. Scale-dependent responses of plant biodiversity to nitrogen enrichment. Ecology 89:2165-2171.

Chen, B. \& D.H. Wise. 1999. Bottom-up limitation of predaceous arthropods in a detritus-based terrestrial food web. Ecology 80:761-772.

Clarke, K.R. 1993. Non-parametric multivariate analyses of changes in community structure. Australian Journal of Ecology 18: 117-143.

Cross, W.F., J.B. Wallace, A.D. Rosemond \& S.L. Eggert. 2006. Whole-system nutrient enrichment increases secondary production in a detritus-based system. Ecology 87:1556-1565.

De Boeck, H.J., I. Nijs, C.M.H.M. Lemmens \& R. Ceulemans. 2006. Underlying effects of spatial aggregation (clumping) in relationships between plant diversity and resource uptake. Oikos 113:269-278.

Fenn, M.E., J.S. Baron, E.B. Allen, H.M. Rueth, K.R. Nydick, L. Geiser, W.D. Bowman, J.O. Sickman, T. Meixner, D.W. Johnson \& P. Neitlich. 2003. Ecological effects of nitrogen deposition in the western United States. BioScience 53:404 420.

Galloway, J.N., J.D. Aber, J.W. Erisman, S.P. Seitzinger, R.W. Howarth, E.B. Cowling \& B.J. Cosby. 2003. The nitrogen cascade. BioScience 53:341-355.

Greenslade, P.J.M. 1964. Pitfall trapping as a method for studying populations of Carabidae (Coleoptera). Journal of Animal Ecology 33:301-310.

Grime, J.P. 1973. Control of species density in herbaceous vegetation. Journal of Environmental Management 1:151-167.

Haddad, N.M., J. Haarstad \& D. Tilman. 2000. The effects of longterm nitrogen loading on grassland insect communities. Oecologia 124:73-84

Haddad, N.M., D. Tilman, J. Harstaad, M. Ritchie \& J.M.H. Knops 2001. Contrasting effects of plant richness and composition on insect communities: a field experiment. American Naturalist 158:17-35.

Halaj, J., A.B. Cady \& G.W. Uetz. 2000. Modular habitat refugia enhance generalist predators and lower plant damage in soybeans. Environmental Entomology 29:383-393.

Halaj, J. \& D.H. Wise. 2002. Impact of a detrital subsidy on trophic cascades in a terrestrial grazing web. Ecology 83:3141-3151. 
Harwood, J.D., K.D. Sunderland \& W.O.C. Symondson. 2001. Living where the food is: web-location by linyphiid spiders in relation to prey availability in winter wheat. Journal of Applied Ecology 38:88-99.

Hättenschwiler, S. \& P. Gasser. 2005. Soil animals alter plant litter diversity effects on decomposition. Proceedings of the National Academy of Sciences of the USA 102:1519-1524.

Hättenschwiler, S., A.V. Tiunov \& S. Scheu. 2005. Biodiversity and litter decomposition in terrestrial ecosystems. Annual Review of Ecology, Evolution and Systematics 36:191-218.

Hector, A., B. Schmid, C. Beierkuhnlein, M.C. Caldeira, M. Diemer, P.G. Dimitrkopoulos, J.A. Finn, H. Freitas, P.S. Giller, J. Good, R. Harris, P. Högberg, K. Huss-Danell, J. Joshi, A. Jumpponen, C. Körner, P.W. Leadley, M. Loreau, A. Minns, C.P.H. Mulder, G. O'Donovan, S.J. Otway, J.S. Pereira, A. Prinz, D.J. Read, M. Scherer-Lorenzen, E-D. Schulze, A-S.D. Siamantziouras, E.M. Spehn, A.C. Terry, A.Y. Troumbis, F.I. Woodward, S. Yachi \& J.H. Lawton. 1999. Plant diversity and productivity experiments in European grasslands. Science 286:1123-1127.

Hooper, D.U. \& P.M. Vitousek. 1998. Effects of plant competition and diversity on nutrient cycling. Ecological Monographs 68:121-149.

Hutchings, M.J. \& I.K. Bradbury. 1986. Ecological perspectives on clonal perennial plants. BioScience 36:178-182.

Knops, J.M.H., D. Tilman, N.M. Haddad, S. Naeem, C.E. Mitchell, J. Haarstad, M.E. Ritchie, K.M. Howe, P.B. Reich, E. Siemann \& J. Groth. 1999. Effects of plant species richness on invasions dynamics, disease outbreaks, insect abundances and diversity. Ecology Letters 2:286-293.

Köchy, M. \& S.D. Wilson. 2005. Variation in nitrogen deposition and available soil nitrogen in a forest-grassland ecotone in Canada. Landscape Ecology 20:191-202.

Kruskal, J.B. 1964. Nonmetric multidimensional scaling: a numerical method. Psychometrika 29:115-129.

Larsen, T.H., N. Williams \& C. Kremen. 2005. Extinction order and altered community structure rapidly disrupt ecosystem functioning. Ecology Letters 8:538-547.

Lawton, J.H. 1983. Plant architecture and the diversity of phytophagous insects. Annual Review of Entomology 28:23-29.

Long, Z.T., C.L. Mohler \& W.P. Carson. 2003. Extending the resource concentration hypothesis to plant communities: effects of litter and herbivores. Ecology 84:652-665.

Martinko, E.A., R.H. Hagen \& J.A. Griffith. 2006. Successional change in the insect community of a fragmented landscape. Landscape Ecology 21:711-721.

McCann, K.S. 2000. The diversity-stability debate. Nature 405:228-233.

McCune, B. \& M.J. Mefford. 2006. Multivariate Analysis of Ecological Data Version 5.14. MjM Software, Gleneden Beach, Oregon, USA.

Mielke, P.W., Jr. 1984. Meteorological applications of permutations techniques based on distance functions. Pp. 813-830. In Handbook of Statistics, Volume 4. (P.R. Krishnaiah \& P.K. Sen, eds.). Elsevier, St. Louis, Missouri, USA.

Moore, J.C., E.L. Berlow, D.C. Coleman, P.C. de Ruiter, Q. Dong, A. Hastings, N.C. Johnson, K.S. McCann, K. Melville, P.J. Morin, A.D. Rosemond, D.M. Post, J.L. Sabo, K.M. Scow, M.J. Vanni \& D.H. Wall. 2004. Detritus, trophic dynamics, and biodiversity. Ecology Letters 7:584-600.

Patrick, L.B., L.H. Fraser \& M.W. Kershner. 2008a. Large-scale manipulation of plant litter and fertilizer in a managed successional temperate grassland. Plant Ecology 197:183-195.

Patrick, L.B., L.H. Fraser \& M.W. Kershner. 2008b. "Brown” world invertebrates contradict "green" world biodiversity theory. Research Letters in Ecology 2008, Article ID 694638. doi:10.11155/ 2008/694638.
Phillips, I.D. \& T.P. Cobb. 2005. Effect of habitat structure and lid transparency on pitfall catches. Environmental Entomology 34:875-882.

Platnick, N.I. 2012. The World Spider Catalog, version 12.5. American Museum of Natural History, online at http://research. amnh.org/entomology/spiders/catalog/index.html

Ricklefs, R.E. \& G.L. Miller. 2000. Ecology. Freeman, New York, USA.

Ritchie, A. \& J.R. Steiger. 1974. Soil Survey of Summit County, Ohio. United States Department of Agriculture, Soil Conservation Service in cooperation with Ohio Department of Natural Resources, Division of Lands and Soil and the Ohio Agricultural Research and Development Center.

Romero, S. \& J.D. Harwood. 2010. Prey utilization by a community of linyphiid spiders: variation across diel and seasonal gradients. Biological Control 52:84-90.

Rypstra, A.L., P.E. Carter, R.A. Balfour \& S.D. Marshall. 1999. Architectural modifications of agricultural habitats and their impact on the spider inhabitants. Journal of Arachnology 27:371-377.

Rypstra, A.L., J.M. Schmidt, B.D. Reif, J. DeVito \& M.H. Persons. 2007. Tradeoffs involved in site selection and foraging in a wolf spider: effects of substrate structure and predation risk. Oikos 116:853-863.

SAS Institute Inc. 1999. SAS System for Windows. SAS Institute Inc, Cary, North Carolina, USA.

Seeber, J., G.U.H. Seeber, R. Langel, S. Scheu \& E. Meyer. 2008. The effect of macro-invertebrates and plant litter of different quality on the release of $\mathrm{N}$ from litter to plant on alpine pastureland. Biology and Fertility of Soils 44:783-790.

Semmartin, M., M.R. Aguiar, R.A. Distel, A.S. Moretto \& C.M. Ghersa. 2004. Litter quality and nutrient cycling affected by grazing-induced species replacements along a precipitation gradient. Oikos 107:148-160.

Strong, D.R., J.H. Lawton \& R. Southwood. 1984. Insects on Plants: Community Patterns and Mechanisms. Harvard University Press, Cambridge, Massachusetts, USA.

Suding, K.N., S.L. Collins, L. Gough, C. Clark, E.E. Cleland, K.L. Gross, D.G. Milchunas \& S. Pennings. 2005. Functional- and abundance-based mechanisms explain diversity loss due to $\mathrm{N}$ fertilization. Proceedings of the National Academy of Sciences of the USA 102:4387-4392.

Tilman, D., J. Knops, D. Wedin \& P. Reich. 2002. Experimental and observational studies of diversity, productivity, and stability. Pp. 42-70. In The Functional Consequences of Biodiversity. (A.P. Kinzig, S.W. Pacala \& D. Tilman, eds.). Princeton University Press, Princeton, New Jersey, USA.

Turkington, R., E. John, S. Watson \& P. Seccombe-Hett. 2002. The effects of fertilization and herbivory on the herbaceous vegetation of the boreal forest in north-western Canada: a 10-year study. Journal of Ecology 90:325-337.

Uetz, G.W. 1979. The influence of variation in litter habitats on spider communities. Oecologia 40:29-42.

Uetz, G.W. 1991. Habitat structure and spider foraging. Pp. 325-348. In Habitat Structure: The Physical Arrangement of Objects in Space. (S.S. Bell, E.D. McCoy \& H.R. Mushinsky, eds.). Chapman and Hall, London, UK.

Uetz, G.W., J. Halaj \& A.B. Cady. 1999. Guild structure of spiders in major crops. Journal of Arachnology 27:270-280.

US EPA. 2005. Clean air status and trends network (CAST-NET). Online at http://www.epa.gov/castnet/

Vitousek, P.M., H.A. Mooney, J. Lubchenco \& J.M. Melillo. 1997. Human domination of Earth's ecosystems. Science 277:494 499.

Wardle, D.A. 2002. Communities and Ecosystems: Linking the Aboveground and Belowground Components. Princeton University Press, Princeton, New Jersey, USA. 
Wardle, D.A. 2006. The influence of biotic interactions on soil biodiversity. Ecology Letters 9:870-886.

Wise, D.H. 1993. Spiders in Ecological Webs. Cambridge University Press, Cambridge, UK.

Wise, D.H. 2004. Wandering spiders limit densities of a major microbedetritivore in the forest-floor food web. Pedobiologia 48:181-188.

Wise, D.H. 2006. Cannibalism, food limitation, intraspecific competition, and the regulation of spider populations. Annual Review of Entomology 51:441-465.
Wise, D.H., W.E. Snyder, P. Tuntibunpakul \& J. Halaj. 1999. Spiders in decomposition food webs of agroecosystems: theory and evidence. Journal of Arachnology 27:363-370.

Worm, B. \& J.E. Duffy. 2003. Biodiversity, productivity, and stability in real food webs. Trends in Ecology and Evolution 18:628632.

Manuscript received 19 December 2011, revised 7 August 2012. 